\title{
On the role of horizontal resolution over the Tibetan Plateau in the REMO regional climate model
}

\author{
Jingwei Xu1,2,3@ $\cdot$ Nikolay Koldunov ${ }^{4,5} \cdot$ Armelle Reca C. Remedio $^{2} \cdot$ Dmitry V. Sein $^{5,6} \cdot$ Xiefei Zhi $^{1} \cdot$ Xi Jiang $^{1}$. \\ Min $\mathrm{Xu}^{7} \cdot$ Xiuhua $\mathrm{Zhu}^{8} \cdot \mathrm{Klaus}$ Fraedrich ${ }^{1,3} \cdot$ Daniela Jacob $^{2}$
}

Received: 2 July 2017 / Accepted: 11 January 2018

(c) Springer-Verlag GmbH Germany, part of Springer Nature 2018

\begin{abstract}
A number of studies have shown that added value is obtained by increasing the horizontal resolution of a regional climate model to capture additional fine-scale weather processes. However, the mechanisms leading to this added value are different over areas with complicated orographic features, such as the Tibetan Plateau (TP). To determine the role that horizontal resolution plays over the TP, a detailed comparison was made between the results from the REMO regional climate model at resolutions of 25 and $50 \mathrm{~km}$ for the period 1980-2007. The model was driven at the lateral boundaries by the European Centre for Medium-Range Weather Forecasts Interim Reanalysis data. The experiments differ only in representation of topography, all other land parameters (e.g., vegetation characteristics, soil texture) are the same. The results show that the high-resolution topography affects the regional air circulation near the ground surface around the edge of the TP, which leads to a redistribution of the transport of atmospheric water vapor, especially over the Brahmaputra and Irrawaddy valleys-the main water vapor paths for the southern TP-increasing the amount of atmospheric water vapor transported onto the TP by about $5 \%$. This, in turn, significantly decreases the temperature at $2 \mathrm{~m}$ by $>1.5{ }^{\circ} \mathrm{C}$ in winter in the high-resolution simulation of the southern TP. The impact of topography on the $2 \mathrm{~m}$ temperature over the TP is therefore by influencing the transport of atmospheric water vapor in the main water vapor paths.
\end{abstract}

Keywords REMO regional climate model $\cdot$ Validation $\cdot$ High-resolution $\cdot$ Added value $\cdot$ Tibetan Plateau

This paper is a contribution to the special issue on East Asian Climate under Global Warming: Understanding and Projection, consisting of papers from the East Asian Climate (EAC) community and the 13th EAC International Workshop in Beijing, China on 24-25 March 2016, and coordinated by Jianping Li, Huang-Hsiung Hsu, Wei-Chyung Wang, Kyung-Ja Ha, Tim Li, and Akio Kitoh.

Jingwei Xu

xu_jw@sina.cn

1 Key Laboratory of Meteorological Disaster, Ministry of Education (KLME)/Joint International Research Laboratory of Climate and Environment Change (ILCEC)/ Collaborative Innovation Center on Forecast and Evaluation of Meteorological Disasters (CIC-FEMD)/Joint Center for Data Assimilation Research and Applications, Nanjing University of Information Sciences and Technology (NUIST), Nanjing 210044, China

2 Climate Service Center Germany (GERICS)/Helmholtz-Zentrum Geesthacht (HZG), Hamburg 20095, Germany

3 Max Planck Institute for Meteorology, Bundesstrasse 53, Hamburg 20146, Germany

\section{Introduction}

Many studies in recent years have shown that results of regional climate models (RCMs) can be improved by increasing the horizontal resolution (Borscheid 2015; Jacob

4 MARUM-Center for Marine Environmental Sciences, Bremen, Germany

5 Alfred Wegener Institute (AWI), Bremerhaven 27568, Germany

6 Shirshov Institute of Oceanology, Russian Academy of Science, 36 Nahimovskiy prospect, Moscow 117997, Russia

7 Meteorological Bureau of Jiangsu Province, Nanjing 210008, China

8 Center for Earth System Research and Sustainability, CliSAP, University of Hamburg, Hamburg 20144, Germany 
et al. 2014; Luca et al. 2012; Lucas-Picher et al. 2012). This added value is more pronounced for extreme weather events, such as extreme precipitation events (Eggert et al. 2015; Gao et al. 2015a; Luca et al. 2012). However, orographic forcing introduces an extra challenge to the simulations in regions with complex topography. For example, the orographic rain bands in the mountains of Myanmar are not simply a local phenomenon, but also anchor the convective center over the Bay of Bengal. These geographical features are therefore an important element of the East Asian monsoon (Xie et al. 2008).

The Tibetan Plateau (TP), often referred to as the third pole of the Earth, has an average elevation of higher than $2000 \mathrm{~m}$ a.s.l. and is the highest plateau in the world, with a dramatic variation in altitude along its edges. It is an important source of water for Asian rivers, including the Ganges-Brahmaputra river system in India and the Yangtze and Yellow rivers in China. It is often considered to be the largest area of ice outside the polar regions (Xu et al. 2008). Water vapor over the TP largely originates from the Bay of Bengal and the Indian Ocean (Feng and Zhou 2012; Ge et al. 2017) via river valleys in the southern TP, such as the Brahmaputra and Irrawaddy. The amount of water vapor originating from the western boundary of the region along the southern edge of the TP is $\sim 32 \%$ of that originating from the southern boundary (Feng and Zhou 2012).

Due to complex orography, the TP is very sensitive to the choice of horizontal resolution in RCMs (Gao et al. 2015a, b, 2017). In this study, we applied the regional climate model REMO (Jacob et al. 2007, 2012; Jacob and Podzun 1997; Sein et al. 2014, 2015) to study the impact of model topography in this complex region. Several previous studies have evaluated the behavior of REMO over the TP. Jacob et al. (2012) used the 2009 version of REMO and performed simulations in six Coordinated Regional Climate Downscaling Experiment (CORDEX) domains, including the South Asia domain covering the TP region, at a horizontal resolution of $0.44^{\circ} \times 0.44^{\circ}$ (about $50 \mathrm{~km} \times 50 \mathrm{~km}$ ). They concluded that REMO can capture the cycles of precipitation and temperature of selected catchments in this region. Kumar et al. (2014) reduced the warm bias in northern India by $\sim 1-3{ }^{\circ} \mathrm{C}$ by modifying the soil thermal characteristics in REMO. REMO can capture the components in the lower, middle and upper layers of the South Asia summer monsoon at a horizontal resolution of $50 \mathrm{~km}$ (Saeed et al. 2009, 2012). Zhang et al. (2005) validated an earlier version of REMO in East Asia and found that the model captured the main features of atmospheric circulation in East Asia in the years 1980 and 1990 and successfully reproduced the spatial distribution and seasonal variation in precipitation. REMO also reproduced major precipitation events on a daily scale and the spatial distribution of monsoon rainfall over the TP in the summer of 1998 (Cui et al. 2007). Previous studies have therefore shown that REMO generally performs well over the TP; however, there is still a need to clarify the mechanisms affecting the sensitivity of different parameters to the horizontal resolution of REMO.

We used REMO to simulate the main CORDEX East Asia domain (http://www.cordex.org) at horizontal resolutions of $25 \mathrm{~km} \times 25 \mathrm{~km}$ and $50 \mathrm{~km} \times 50 \mathrm{~km}$. The study aimed to:

- validate $2 \mathrm{~m}$ temperature and precipitation over the TP simulated by REMO and describe the differences between the simulations at resolutions of 25 and $50 \mathrm{~km}$;

- explore the impact of topography on the transport of atmospheric water vapor over the main water vapor paths for the TP; and

- analyze the possible link between the difference in transport of atmospheric water vapor and the difference in $2 \mathrm{~m}$ temperature over the TP.

The structure of the paper is as follows: Sect. 2 describes the validation data, model, experimental setup and interpolation method. In Sect. 3 we evaluate the performance of REMO over the TP, with particular emphasis on the elucidation of the role of topographic resolution. The main conclusions and a discussion are presented in Sect. 4.

\section{Data and experimental setup}

This study used both high-resolution reanalysis data and output data from REMO. All the analyses were based on simulation results in the period 1980-2007. In a similar manner to the work of Ji and Kang (Ji and Kang 2013) this study used seasonal data, although only the winter (December-February, DJF) and summer (June-August, JJA) results are presented here.

\subsection{Reanalysis data and methods}

Many studies (Kumar et al. 2015; Maussion et al. 2014; Palazzi et al. 2013; Winiger et al. 2005) have reported that reanalysis products are more reliable than limited station data for studying the regional climate around the TP. We used gridded $2 \mathrm{~m}$ temperature and precipitation reference data from the Modern-Era Retrospective Analysis for Research and Applications-2 (MERRA-2) version of the Goddard Earth Observing System-5 (GEOS-5) atmospheric general circulation model. The seasonal mean climate of the MERRA-2 version of the GEOS-5 atmospheric general circulation model represents a substantial improvement over the simulated climate of the MERRA1 version at all resolutions and for all applications (Molod et al. 2015).

In order to validate MERRA- 2 over the TP, we use gridded surface air temperature and precipitation observations 
provided by the China Meteorological Administration (CN05.1) with a spatial resolution of $0.25^{\circ} \times 0.25^{\circ}$ (Wu and Gao 2013; Xu et al. 2009). The climatology is first interpolated by thin plate smoothing splines and then a gridded daily anomaly derived from angular distance weighting method is added to climatology to obtain the final dataset. This dataset is generated based on temperature observations from over 2400 stations in China for the period from 1961 to 2012 (Xu et al. 2009).

The previous version of MERRA was evaluated over the TP by (Wang and Zeng 2012). They find that it has a high correlation with observations and reliable at daily and monthly time scales. We also found that the newer MERRA- 2 can capture the spatial pattern of $2 \mathrm{~m}$ temperature and precipitation well at monthly time scale, with $2 \mathrm{~m}$ temperature correlation coefficients around 0.99 and precipitation correlation coefficients between 0.71 (in JJA) and 0.89 (in DJF; Table 1). Over the eastern TP, where the stations are mostly located, MERRA-2 showed smaller $2 \mathrm{~m}$ temperature bias compared to the Western TP where the number of stations is small (Fig. 1a, b). Due to the climatically small precipitation amount in DJF, MERRA-2 overestimates precipitation especially over high elevations (e.g. over the Himalaya Mountains; Fig. 1e). In JJA, MERRA-2 agrees with observations well over the TP (Fig. 1f).

As described previously (Kumar et al. 2015; Maussion et al. 2014; Palazzi et al. 2013; Winiger et al. 2005), reanalysis products are more reliable than limited station data for studying the regional climate around the TP. The range of biases of MERRA-2 is relatively small at monthly mean time scale, so we used MERRA-2 as the reference in this study.

To examine the added value of using simulations at highresolution, we compared the data obtained from simulations at a resolution of $25 \mathrm{~km} \times 25 \mathrm{~km}$ with the data obtained from simulations at a resolution of $50 \mathrm{~km} \times 50 \mathrm{~km}$ with reference to the MERRA- $20.625^{\circ} \times 0.5^{\circ}$ dataset. According to Prein et al. (2016), the added value of a high-resolution simulation is more obvious when model data are compared on the common high-resolution grid because more fine-scale processes can be represented. However, comparison of the 25 and $50 \mathrm{~km}$ simulations on a coarse grid can be considered fair because both resolutions are able to resolve the analyzed features (Casanueva et al. 2015). No artificial value was added when interpolating the high-resolution data into coarser resolutions. After careful consideration, most of the analyses and comparisons were carried out at the coarser resolution.

The first-order conservative interpolation method (Redler 2015) was used to interpolate the results between resolutions. Because the orographic dataset used by REMO is different from that used by MERRA-2, a lapse rate of $0.0064{ }^{\circ} \mathrm{C} \mathrm{m}^{-1}$ is used to calculate the REMO $2 \mathrm{~m}$ temperature to MERRA-2's height. This lapse rate was also used to transfer the $2 \mathrm{~m}$ temperature from the $25 \mathrm{~km}$ simulation orography to the $50 \mathrm{~km}$ simulation orography.

\subsection{Model and experiment setup}

Previous studies have suggested that REMO generally shows a good performance over the TP (Cui et al. 2007; Jacob et al. 2012; Kumar et al. 2014a, 2015; Saeed et al. 2009, 2012), because it can reasonably simulate the general circulation of the Asian monsoon (Zhang et al. 2005). We used REMO to simulate the East Asia domain (Fig. 2) in a setup similar to (Kumar et al. 2014b and; Sein et al. 2015). However, because the western part of the TP is close to the domain boundaries, it is unreasonable to draw conclusions based on the results obtained in this region.

As described previously (Jacob et al. 2012, 2013; Sein et al. 2014, 2015), REMO uses physical parameterizations from ECHAM 4 (Roeckner et al. 2003) and the dynamic framework from the weather forecast model of the German Weather Service Europe-Model/Deutschland-Model (Majewski 1991). Horizontal grid boxes are rotated on an Arakawa-C spherical grid (Simmons and Burridge 1981). The model uses the Tiedtke comprehensive mass flux convection scheme for cumulus parameterization (Tiedtke 1989) and the radiation scheme is calculated after (Ritter and Geleyn 1992). A leap-frog scheme is used with semi-implicit correction and time filtering to minimize numerical effects (Asselin 1972). Following the relaxation scheme of (Davies 1983), no nudging is applied outside the eight points used as boundary conditions. The model atmosphere is divided into 27 layers from the surface to $10 \mathrm{hPa}$. The integration time step is $120 \mathrm{~s}$. The boundary conditions and forcing data are from the European Centre for Medium-Range Weather Forecasts Interim Reanalysis (ERA-Interim) products (Dee et al. 2011). More details about the REMO setup have been

Table 1 Pattern correlation coefficients for seasonal and annual surface air temperature climatology in 1980-2007 between the observation (CN05.1) and MERRA-2

\begin{tabular}{|c|c|c|c|c|c|c|}
\hline & \multicolumn{3}{|c|}{$2 \mathrm{~m}$ temperature } & \multicolumn{3}{|c|}{ Precipitation } \\
\hline & DJF & JJA & Ann & DJF & JJA & Ann \\
\hline MERRA-2 & 0.98 & 0.99 & 0.99 & 0.89 & 0.71 & 0.80 \\
\hline
\end{tabular}

All correlation values passed the two-tailed t-test for statistical significance at the $95 \%$ confidence level 

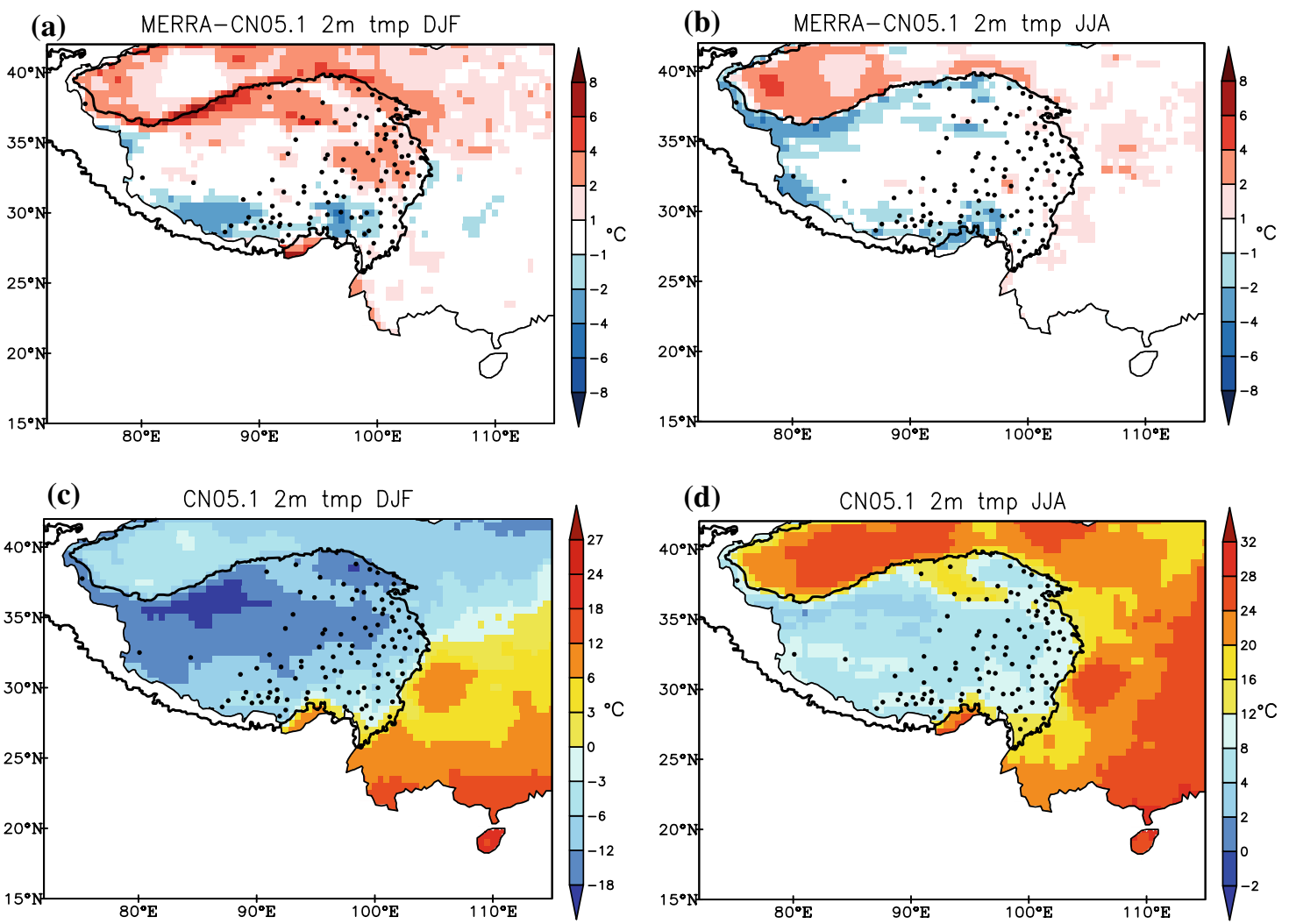

(e) (MERRA-CN05.1)/CN05.1 preci DJF
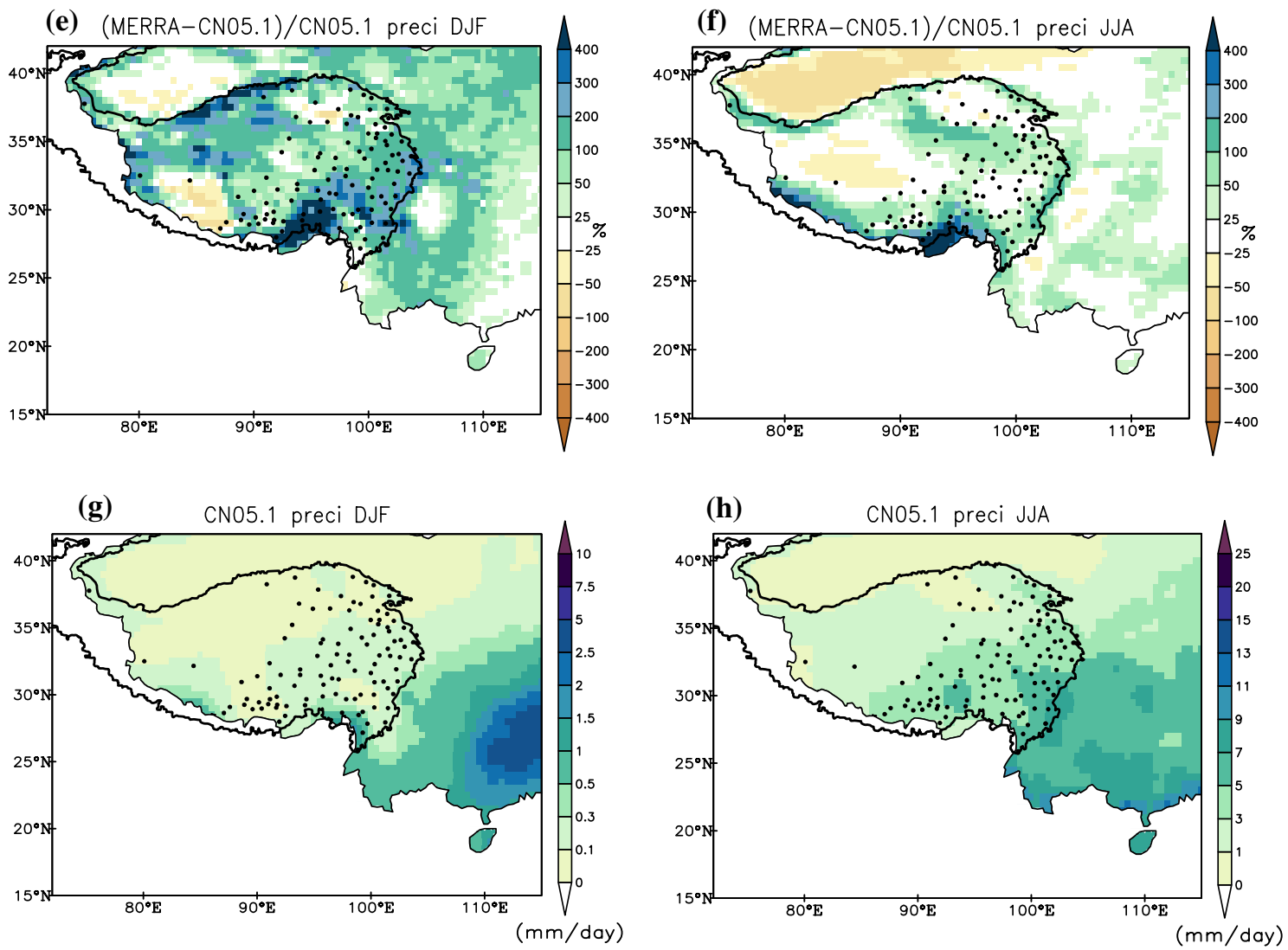
4Fig. 1 Spatial distribution of the monthly mean $2 \mathrm{~m}$ temperature bias $\mathbf{a}$ in DJF, $\mathbf{b}$ in JJA and CN05.1 monthly mean $2 \mathrm{~m}$ temperature $\mathbf{c}$ in DJF, $\mathbf{d}$ in JJA during the period 1980-2007. e-h Are same as a-d, but for precipitation. Black dots indicate the weather observation stations. The solid black line is the $2000 \mathrm{~m}$ a.s.l. contour line over the TP

reported elsewhere (Jacob et al. 2007, 2012, 2013; Jacob and Podzun 1997; Kumar et al. 2014a; Saeed et al. 2009, 2012; Sein et al. 2015). In the following, we call $25 \mathrm{~km} \times 25 \mathrm{~km}$ resolution simulation $\mathrm{R} \_25 \mathrm{~km}$ and $50 \mathrm{~km} \times 50 \mathrm{~km}$ resolution simulation R_50 km.

The model grids were constructed in a way that the four grid boxes of the $25 \mathrm{~km}$ resolution grid covered exactly the same area as one grid box of the $50 \mathrm{~km}$ grid. This was to make sure that the sources of the surface parameters, such as the land-sea mask and soil parameters, used in the four $25 \mathrm{~km}$ grid boxes and the matched $50 \mathrm{~km}$ grid box were the same in REMO. The same data sources were used to prepare the 25 and $50 \mathrm{~km}$ land surface parameters, such as the orographic features and soil texture. Global 30 Arc-Second Elevation Data Set (GTOPO30) data were used as the orographic source data and the global dataset of land surface parameters (Hagemann 2002; Hagemann et al. 1999) was used as the data source for the vegetation parameters. The simulation period was 1980-2007. The two experiments R_25 km and R_50 km were run separately, no nesting was used.

\section{Results}

\subsection{Validation of the $\mathbf{2} \mathbf{m}$ temperature and precipitation}

Similar to most of the GCMs from the fifth phase of the Coupled Model Intercomparison Project (CMIP5) in East Asia ( $\mathrm{Su}$ et al. 2013), REMO captures the spatial-temporal patterns relatively well. Furthermore, the ERA-Interim forcing data used in this study has cold and wet biases over the TP (Bao and Zhang 2013; Su et al. 2013). Compared with the ERA-Interim forcing data, our results show that REMO has a cold bias, whereas an improved wet bias over the TP.

\subsubsection{Seasonal mean $2 \mathrm{~m}$ temperature bias over the TP}

The main purpose of this work was to study the horizontal resolution effects over the TP. We compared the $2 \mathrm{~m}$ temperature data obtained by REMO at two different resolutions with the MERRA-2 $2 \mathrm{~m}$ temperature data. Similar to the ERA-Interim lateral boundary forcing dataset (Bao and Zhang 2013), REMO showed a cold bias over the TP (Fig. 3), while warm biases appear over most of the land masses surrounding the TP (e.g. over North India and South, Central and NW China).

Both simulations generally capture the spatial pattern of $2 \mathrm{~m}$ temperature well. They also remarkably capture the seasonal cycle (Figs. 3a, 4b). The $2 \mathrm{~m}$ temperature bias in the two simulations also showed a distinctive seasonal cycle: the cold bias was greater in the boreal winter than in the summer. Significant cold biases are evident in DJF over the southern and western TP (Fig. 3a, b). The area with the coldest bias in JJA was located in the central and western TP (Fig. 4a, b). The $2 \mathrm{~m}$ temperature in the R_50 km simulation was closer to the reference value than the $2 \mathrm{~m}$ temperature in the R_25 km simulation.

Although the monthly mean cold biases are shown in both simulations all year around (Fig. 5a), the R_50 km simulation shows slightly smaller cold bias and RMSE compared to the values in the $\mathrm{R} \_25 \mathrm{~km}$ simulation (Table 2). Both simulations captured the warming trends over the TP with a warming rate of $0.2^{\circ}-0.6^{\circ} \mathrm{C}$, which is similar to previous studies (Gao et al. 2015b, 2017; Zhu et al. 2013), but underestimated the warming rate from February to April. The R_25 km simulation wars colder over the TP than the $\mathrm{R} \_50 \mathrm{~km}$ simulation the whole year round, but especially in DJF.

\subsubsection{Seasonal mean precipitation bias over the TP}

A distinct seasonal cycle was found in precipitation over the TP. REMO generally captured the seasonal cycle of precipitation well, but with higher wet biases in DJF than in JJA, especially in the central region and in a small area in the southeastern TP. The precipitation in the R_25 km simulation was closer to the reanalysis values than that in the R_50 km simulation. In detail, REMO overestimated the DJF precipitation over a large part of the areas with a complex orography-for example, the overestimation was especially noticeable over the central TP exceeding $400 \%$, while only $>50 \%$ over West India and $>100 \%$ over large parts of China (Fig. 6a, b), indicating a general deficiency in the simulated orographic precipitation with coarse-resolution models in complex terrains (Rasmussen et al. 2011). These results are similar to those obtained in previous studies (Jacob et al. 2012; Saeed et al. 2012). The wet bias decreased to a quarter (about 100\%) over the TP (Fig. 6a, b). Compared with the wet bias in the ERA-Interim dataset (Bao and Zhang 2013) and the majority of the GCMs from CMIP5 (Su et al. 2013), REMO showed a much reduced bias over the TP (Fig. 7).

A distinct cycle was found in the seasonal bias in precipitation over the TP. Due to the climatically small precipitation amount in winter, the relative bias was bigger in DJF than in JJA. The highest monthly mean wet bias presented in December (Fig. 8a). The R_25 km simulation showed 


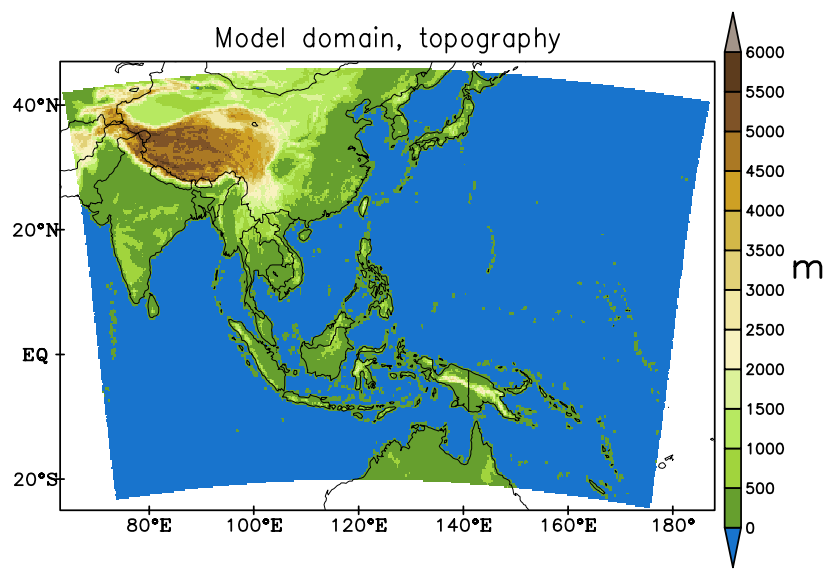

Fig. 2 Simulation domain and topography

a smaller magnitude wetting trend bias compared to the R_50 km simulation all year round (Fig. 8b). The R_25 km simulation had an improved spatial correlation, RMSE, and bias than the R_50 km simulation (Table 3).

We plotted a Taylor diagram (Taylor 2001) to summarize the results. The temperature differences are similar, except for the months September-November (SON). The results from the $\mathrm{R} \_50 \mathrm{~km}$ simulation are relatively closer to the reference values. The simulated seasonal difference in precipitation is greater than the difference in temperature. The $\mathrm{R} \_25 \mathrm{~km}$ simulation produced a distinctive advance in precipitation in every season. It is worth to note that the R_50 km simulation in SON did not pass statistically significant at the $95 \%$ confidence level. The R_25 km simulation was dryer and colder than the R_50 km simulation.

\subsection{Differences in the detailed $\mathbf{2} \mathrm{m}$ temperature and precipitation between the $R \_25 \mathbf{~ k m}$ and $R \mathbf{5 0} \mathbf{~ k m}$ simulations}

The main purpose of this work is to study the impact of horizontal resolution over the TP. As mentioned in the experiments setup section, in order to ensure that the matched grid boxes from the R_25 km and R_50 km simulations represented the similar prescribed surface forcing over land (e.g., vegetation characteristics, soil texture), computational grids were prepared in a way that the four grid boxes from the R_25 km simulation exactly overlay the grid box from the R_50 km simulation. Both simulations were run separately. We also interpolated the results from the $\mathrm{R} \_25 \mathrm{~km}$ grid into the R_50 km grid for comparison (Fig. 9). (a) R_25km-MERRA $2 \mathrm{~m}$ tmp DJF
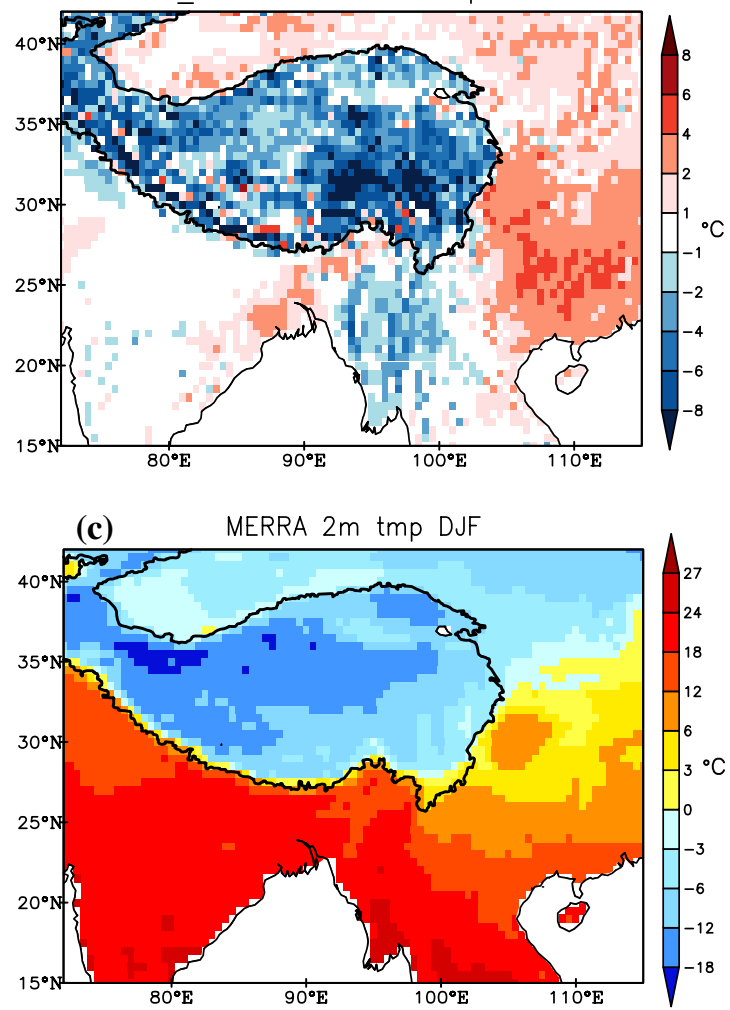

(b) R_50km-MERRA $2 \mathrm{~m}$ tmp DJF

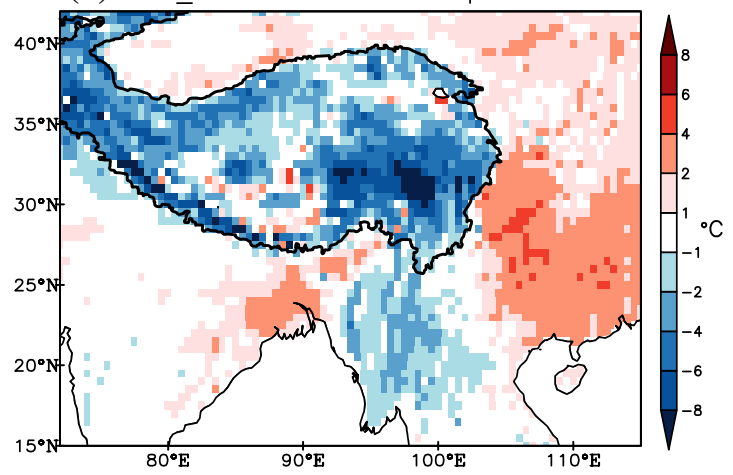

Fig. 3 Spatial distribution of the monthly mean $2 \mathrm{~m}$ temperature bias in DJF in the a R_25 $\mathrm{km}$ and $\mathbf{b}$ R_50 km simulations and $\mathbf{c}$ in the MERRA-2 dataset during the period 1980-2007 

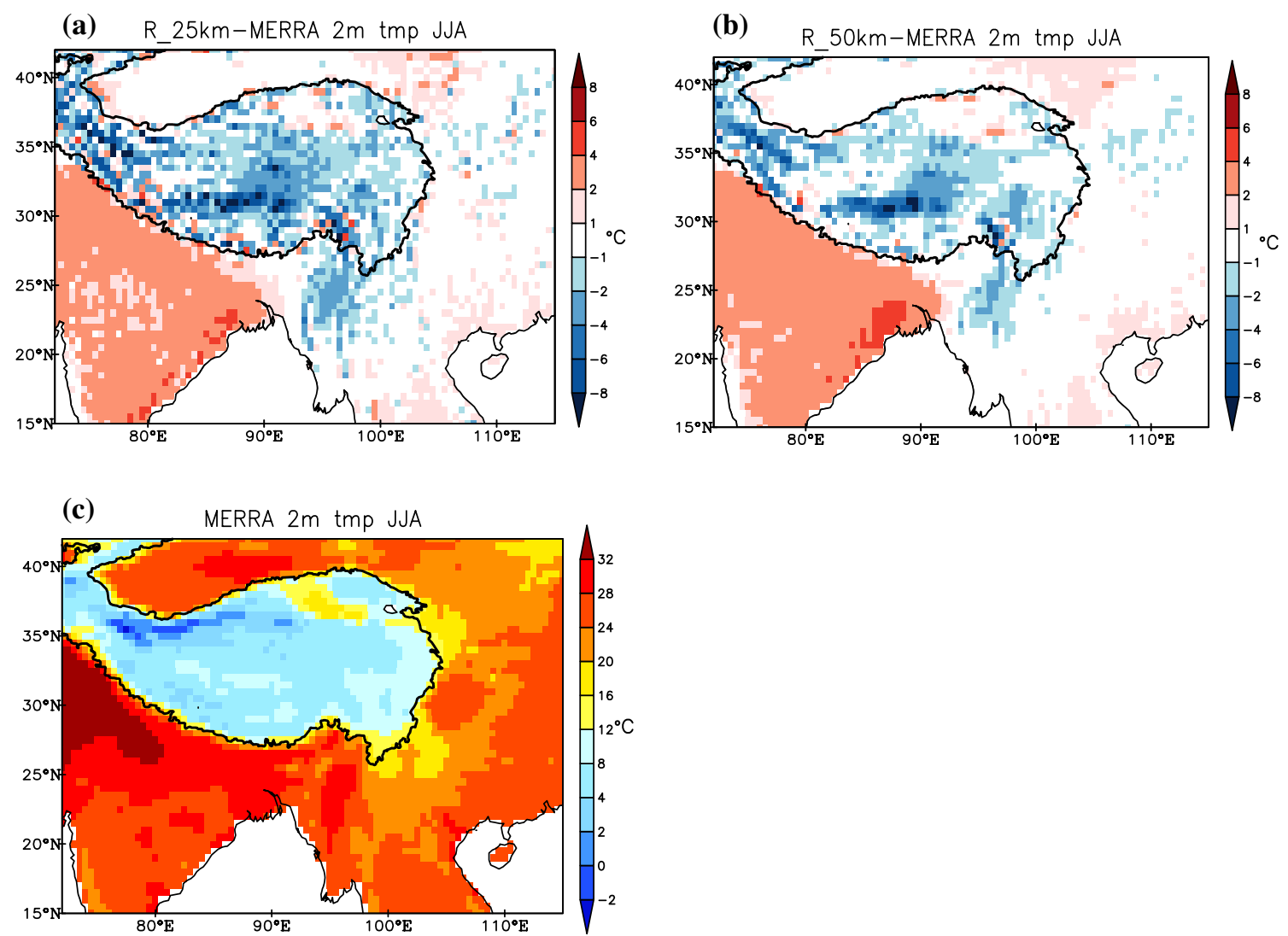

Fig. 4 same as Fig. 2, but for JJA
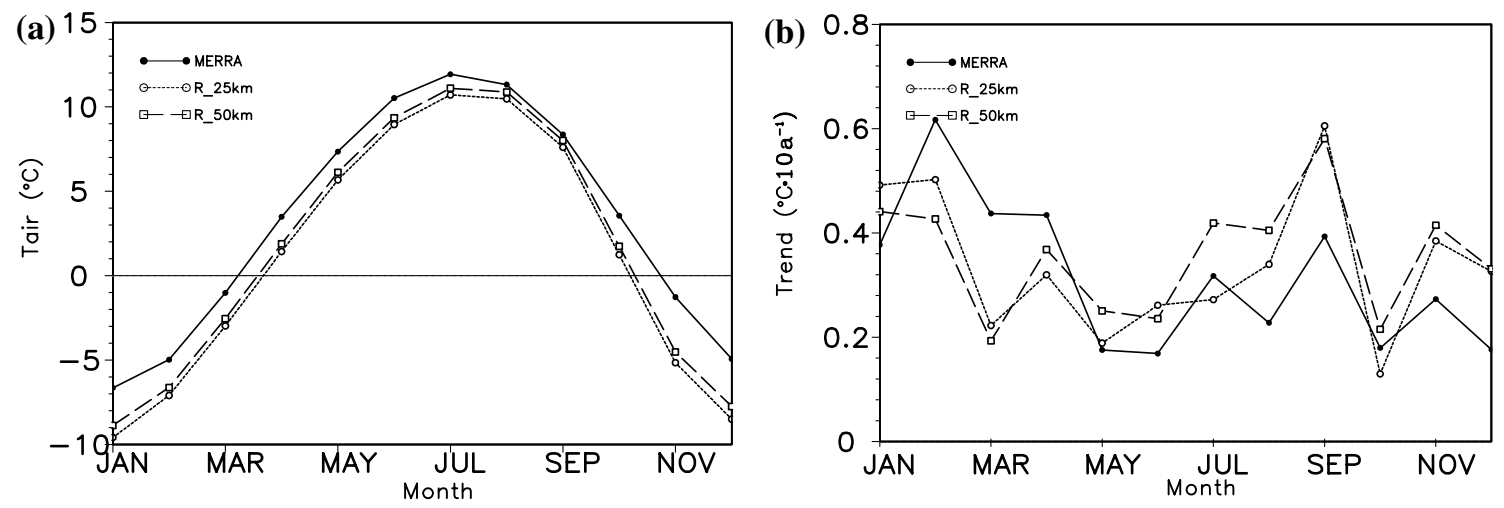

Fig. 5 a Monthly mean variation in the $2 \mathrm{~m}$ temperature (Tair) and $\mathbf{b}$ the trend in the $2 \mathrm{~m}$ temperature compared with the variation in MERRA-2 from 1980 to 2007

The $2 \mathrm{~m}$ temperature from the $\mathrm{R} \_25 \mathrm{~km}$ simulation was lower than that from the R_50 km simulation over the TP all year round, although the difference was greater in DJF than in JJA (Fig. 10a, b). The largest $2 \mathrm{~m}$ temperature difference was located in the southern TP. In terms of the precipitation, the greatest differences were located in the southern and western TP. (Fig. 10c, d). These differences and the results reported in Sect. 3.1 indicate that the R_25 km simulation produced colder and drier conditions over the TP than the R_50 km simulation, especially in the southern and western TP. However, the results in western TP were close to the western boundary of the simulation domain, which could lead to model boundary issues. We, therefore, focused on the southern TP, where the main water vapor transport is via river valleys, such as valleys of the Brahmaputra and Irrawaddy. 
Table 2 Results for MERRA-2 dataset and the simulated the seasonal and annual $2 \mathrm{~m}$ temperature from 1980 to 2007 (units: ${ }^{\circ} \mathrm{C}$ )

\begin{tabular}{|c|c|c|c|c|c|c|c|c|c|c|c|c|}
\hline & \multicolumn{3}{|l|}{ Mean } & \multicolumn{3}{|l|}{ Bias } & \multicolumn{3}{|c|}{ RMSE } & \multicolumn{3}{|c|}{ CORR } \\
\hline & DJF & JJA & Ann & DJF & JJA & Ann & DJF & JJA & Ann & DJF & JJA & Ann \\
\hline MERRA-2 & -5.52 & 11.25 & 3.07 & & & & & & & & & \\
\hline R_25 km & -8.38 & 10.04 & 0.99 & -2.86 & -1.21 & -2.08 & 2.90 & 1.23 & 2.09 & 0.96 & 0.97 & 0.97 \\
\hline R_50 km & -7.72 & 10.44 & 1.50 & -2.20 & -0.81 & -1.57 & 2.25 & 0.86 & 1.59 & 0.97 & 0.98 & 0.98 \\
\hline
\end{tabular}

MERRA-2 is the average $2 \mathrm{~m}$ temperature over the whole TP; the bias and RMSE values summarize the errors in the MERRA-2 reanalysis dataset as the references at all grid points over the TP; CORR is the correlation coefficient for the $2 \mathrm{~m}$ temperature between MERRA-2 and simulations. All CORR values passed the two-tailed t-test for statistical significance at the $95 \%$ confidence level
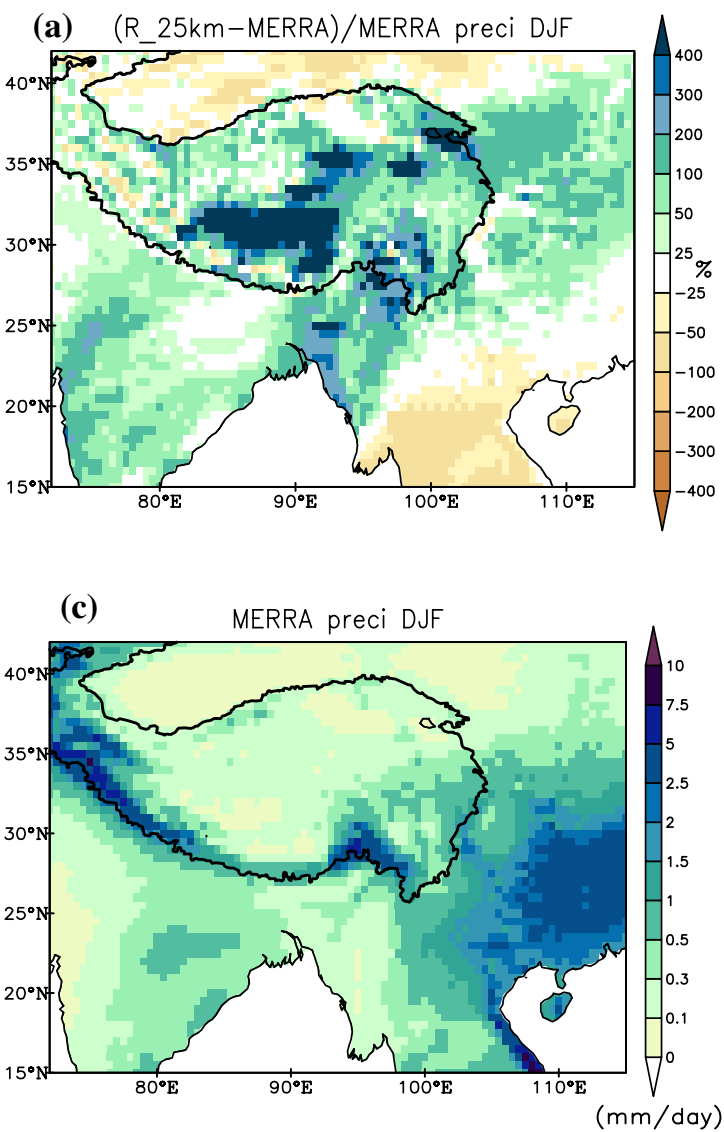

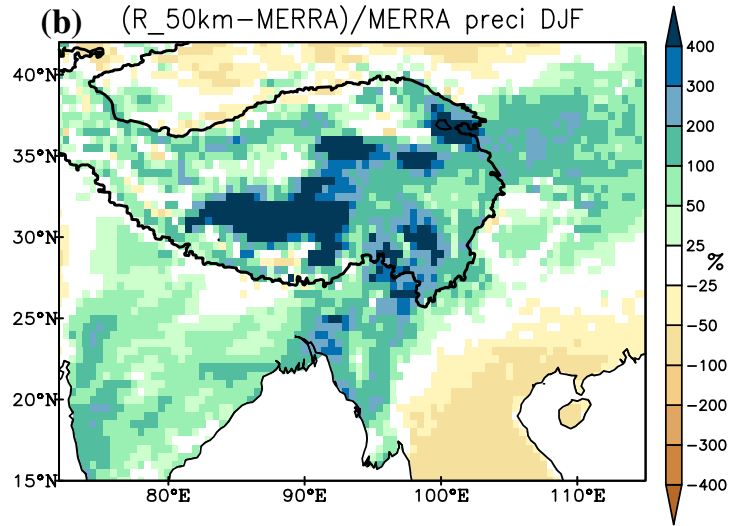

Fig. 6 Spatial distribution of the monthly mean precipitation bias in DJF in the a R_25 km and $\mathbf{b}$ R_50 km simulations and $\mathbf{c}$ in the MERRA-2 dataset during the period 1980-2007

\subsection{The impact of topography on the transport of atmospheric water vapor}

Most of the datasets used for preparation of surface forcing over land (e.g., vegetation characteristics, soil texture) had a resolution of $\sim 1^{\circ} \times 1^{\circ}$ (Claussen et al. 1994; Rechid et al. $2009 \mathrm{a}, \mathrm{b})$, which is coarser than our experiments horizontal resolutions of $25 \mathrm{~km} \times 25 \mathrm{~km}$ and $50 \mathrm{~km} \times 50 \mathrm{~km}$. So there are only small differences in the surface forcing between the R_25 km simulation and the R_50 km simulation, except for the orographic data, obtained from GTOPO30 (Miliaresis and Argialas 1999).

To examine the differences in the topography between simulations, the nearest neighbor remapping was applied to remap the topography from the $\mathrm{R} \_50 \mathrm{~km}$ simulation into the $\mathrm{R} \_25 \mathrm{~km}$ simulation grid cells. The greatest differences in topography were along the edge of the TP (Fig. 11a). The differences in height are usually along the main rivers (blue lines in Fig. 11b), indicating the river valleys (e.g. the Brahmaputra and Irrawaddy valleys) were broader or deeper in 

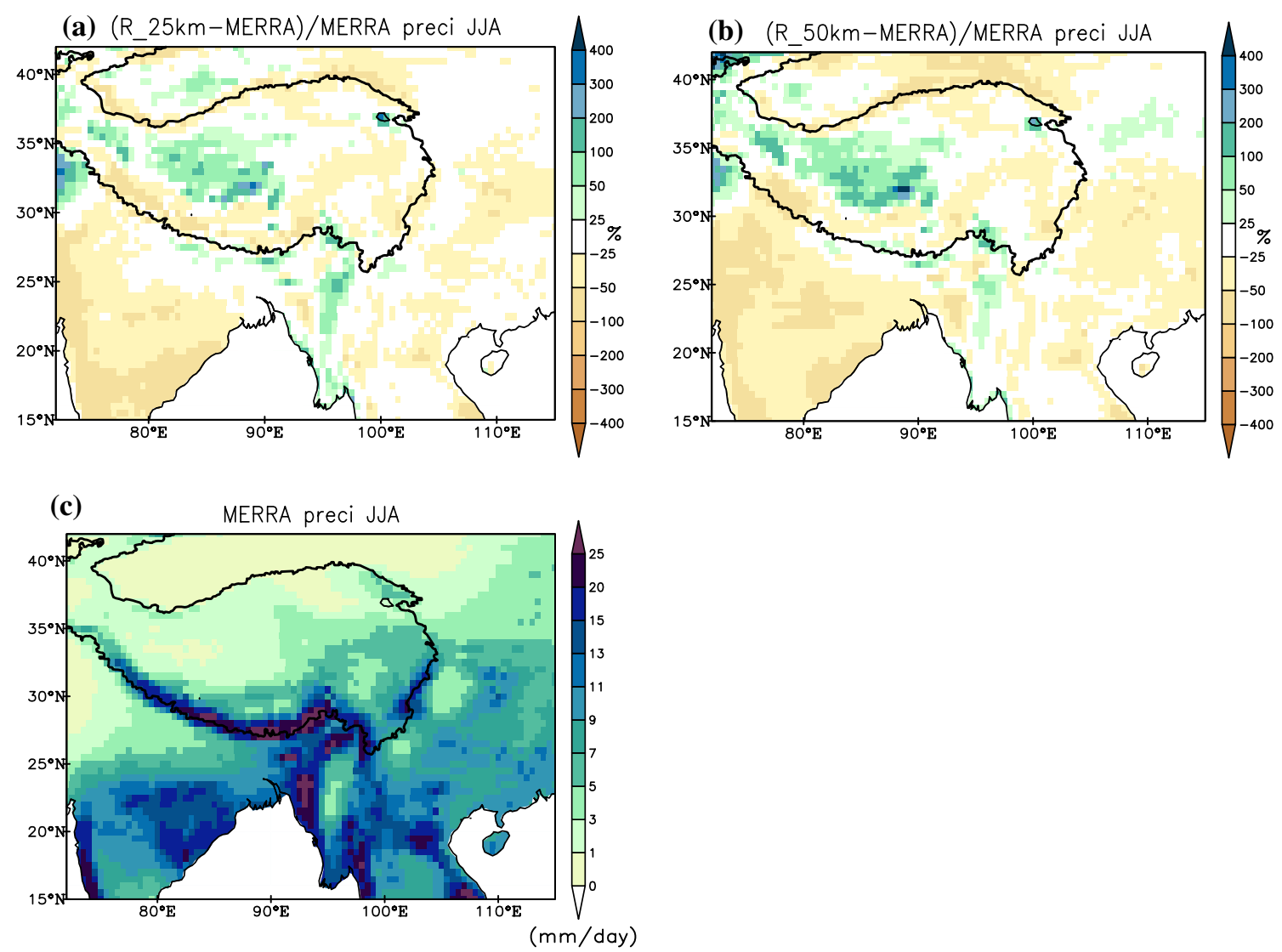

Fig. 7 same as Fig. 6, but for JJA
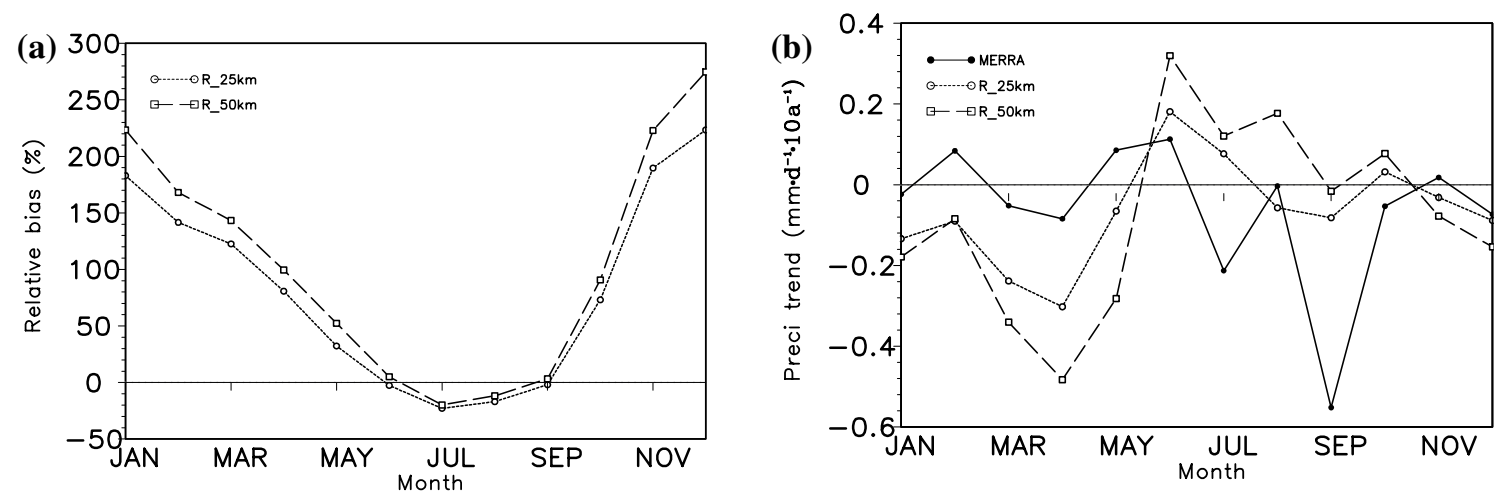

Fig. 8 Annual cycle of the relative bias in monthly precipitation of a the two simulations and $\mathbf{b}$ the trend compared with MERRA-2 in the period 1980-2007

the R_25 km simulation than in the R_50 km simulation (Fig. 11b).

The enlarged valleys in the $\mathrm{R} \_25 \mathrm{~km}$ simulation disrupted the surface winds between the Hengduan Mountains and the Brahmaputra valley in the R_50 km simulation. We constructed a cross-section of the orographic features and the wind speed at $10 \mathrm{~m}$ height along $24.5^{\circ} \mathrm{N}$ between $97^{\circ} \mathrm{E}$ and $105^{\circ} \mathrm{E}$ across an area of horizontal wind direction shear in the Hengduan Mountains, which is one of the source regions for the Southwest China Vortex (Wu et al. 2011). The cross-section showed that there were many low elevation regions in the topography in the R_25 km simulation compared with the R_50 km simulation (Fig. 12b). This means that the blocking effect of the topography in the R_25 km simulation was smaller than that in the R_50 km simulation and the wind speed at 
Table 3 Same as Table 2, but for precipitation (units: $\mathrm{mm} /$ day)

\begin{tabular}{|c|c|c|c|c|c|c|c|c|c|c|c|c|}
\hline & \multicolumn{3}{|c|}{ Mean } & \multicolumn{3}{|l|}{ Bias } & \multicolumn{3}{|c|}{ RMSE } & \multicolumn{3}{|c|}{ CORR } \\
\hline & DJF & JJA & Ann & DJF & JJA & Ann & DJF & JJA & Ann & DJF & JJA & Ann \\
\hline MERRA-2 & 0.64 & 7.00 & 3.11 & & & & & & & & & \\
\hline R_25 km & 1.76 & 5.94 & 3.70 & 1.12 & -1.06 & 0.59 & 1.13 & 1.04 & 0.63 & 0.56 & 0.87 & 0.74 \\
\hline R_50 km & 1.99 & 6.30 & 4.03 & 1.35 & -0.70 & 0.92 & 1.37 & 1.24 & 0.95 & 0.53 & 0.86 & 0.72 \\
\hline
\end{tabular}

MERRA-2 is the average precipitation over the whole TP; the bias and RMSE values summarize the errors in the MERRA-2 reanalysis dataset as the references at all grid points over the TP; CORR is the correlation coefficient for the precipitation between MERRA-2 and simulations. All CORR values passed the twotailed $\mathrm{t}$-test for statistical significance at the $95 \%$ confidence level (a)

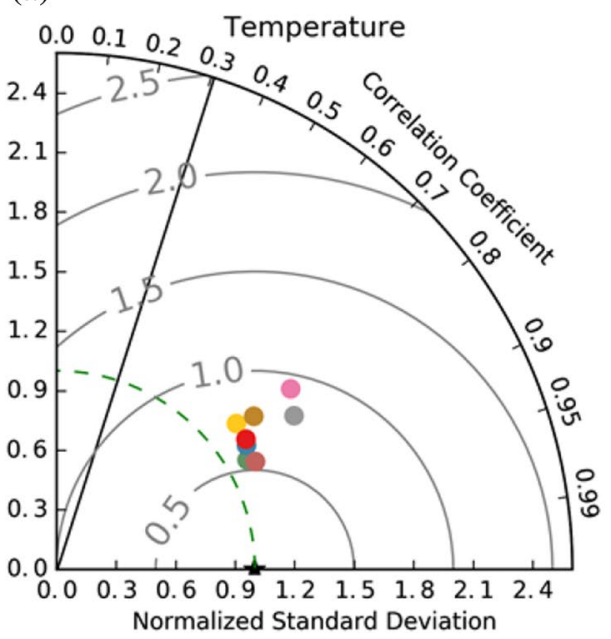

(b)

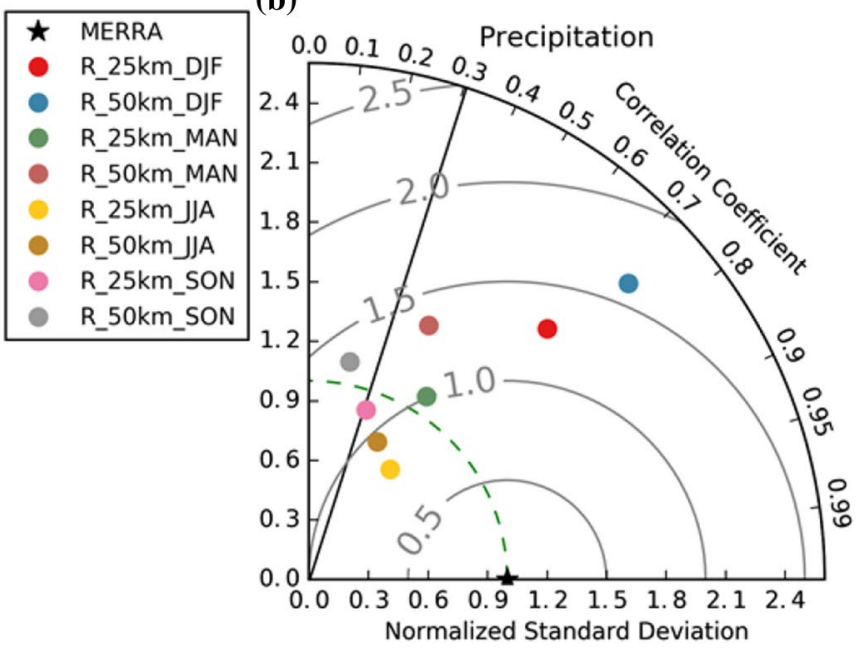

Fig. 9 Analysis of the seasonal a $2 \mathrm{~m}$ temperature and b precipitation over the TP in 1980-2007. The black line shows the statistically significant correlation at the $95 \%$ confidence level based on the two-tailed t-test with the MERRA-2 reanalysis as the reference

$10 \mathrm{~m}$ was, therefore, faster (Fig. 12a). These results show that the enlarged river valleys in the R_25 km simulation reduce the blocking effect of the Hengduan Mountains for the low elevation regions in the topography.

Given the altitude of the Hengduan Mountains, we plotted the difference in wind speed at $925 \mathrm{hPa}$ to show the relationship between the blocking effect of the Hengduan Mountains and the amount of water vapor transported over the TP. The area of horizontal wind shear in the southern Hengduan Mountains is marked by the red boxes in Fig. 13 . The density of the wind streamlines shows that the air flows converge over the river valleys (the Venturi effect). Wang and Tan (2014) reported that the Hengduan Mountains block the prevailing southwesterly winds in DJF and the southerly winds in JJA, forcing the blocked air to flow up the mountains and onto the TP.

Because the low elevation regions in the topography in the $\mathrm{R} \_25 \mathrm{~km}$ simulation reduce the blocking effect of the Hengduan Mountains, it is easier for air to pass through the Hengduan Mountains via the enlarged river valleys in the $\mathrm{R} \_25 \mathrm{~km}$ simulation. We found faster wind speeds for the southwesterly (southerly) winds in DJF (in JJA; marked by red boxes in Fig. 13c, f).

The main mechanism of the blocking effect of the Hengduan Mountains on the transport of water vapor over the TP is caused by the S-shaped Himalaya and Hengduan mountain ranges. This S-shape means that the Brahmaputra valley, the main transport path for water to the southern TP, is a backwater area. A large amount of air escaping from the blocking by the effect of the Hengduan Mountains in the R_25 km simulation, whereas air flows up over the TP in the R_50 km simulation. This, in turn, affects the transport of water vapor and vertical movement of air over the TP. The key factor is that the enlarged valleys in the $\mathrm{R} \_25 \mathrm{~km}$ simulation reduce the blocking effect of the Hengduan Mountains.

In order to analyze the difference in vertical movement of air and the transport of water vapor, we plotted the differences in geopotential height at $850,500,600$ and $200 \mathrm{hPa}$ between the R_25 km and R_50 km simulations. Figure 14 shows that there were positive differences in geopotential height in the surface layer, whereas negative differences were present in the upper layer, suggesting that less air flows 

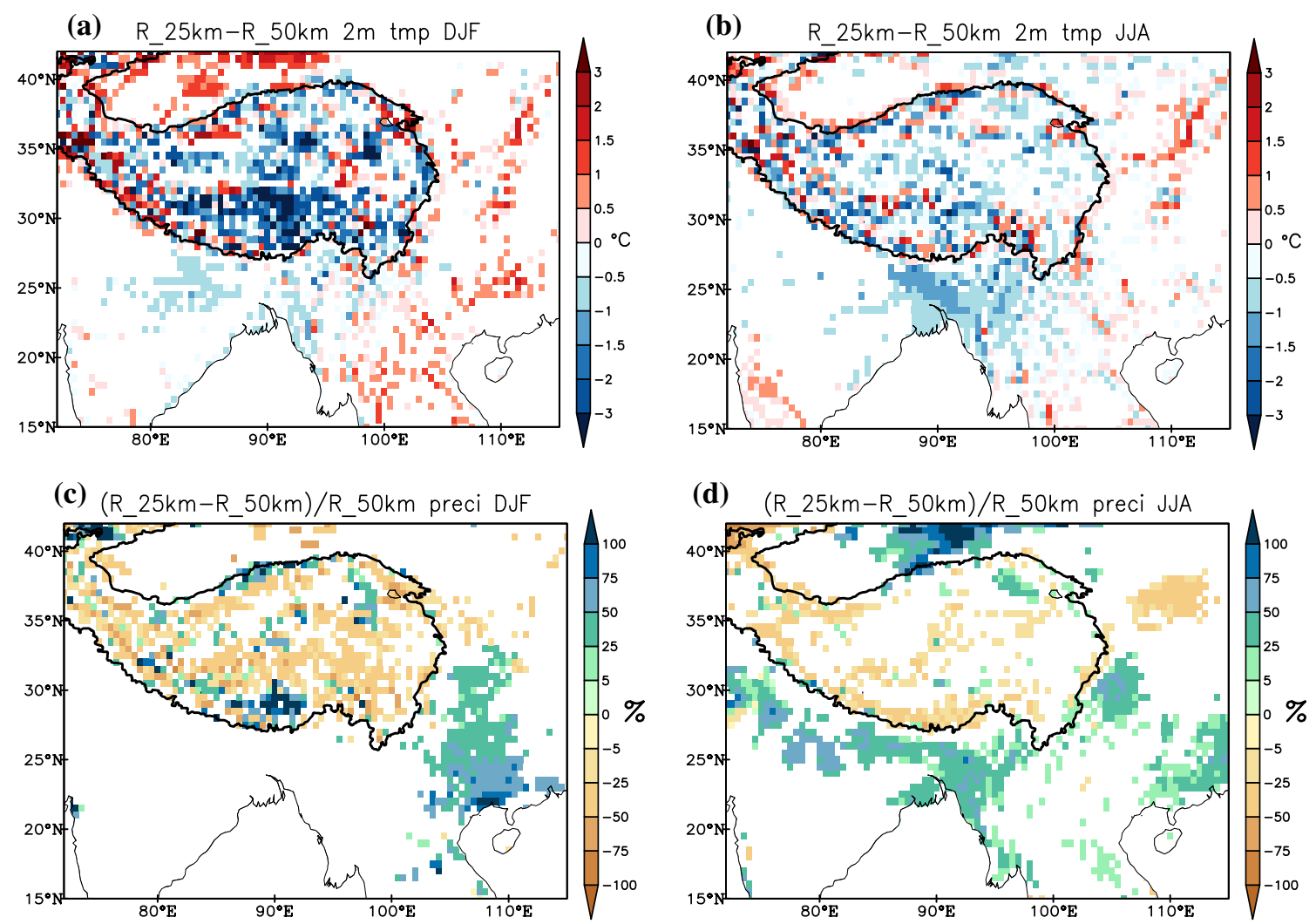

Fig. 10 Differences in $\mathbf{a}, \mathbf{b}$ the $2 \mathrm{~m}$ temperature and $\mathbf{c}, \mathbf{d}$ monthly mean precipitation of the $\mathrm{R} \_25 \mathrm{~km}$ and $\mathrm{R} \_50 \mathrm{~km}$ simulations in $\mathbf{a}, \mathbf{c}$ DJF and b, d JJA during the period 1980-2007. All the differences were statistically significant at the $95 \%$ confidence level based on the two-tailed t-test
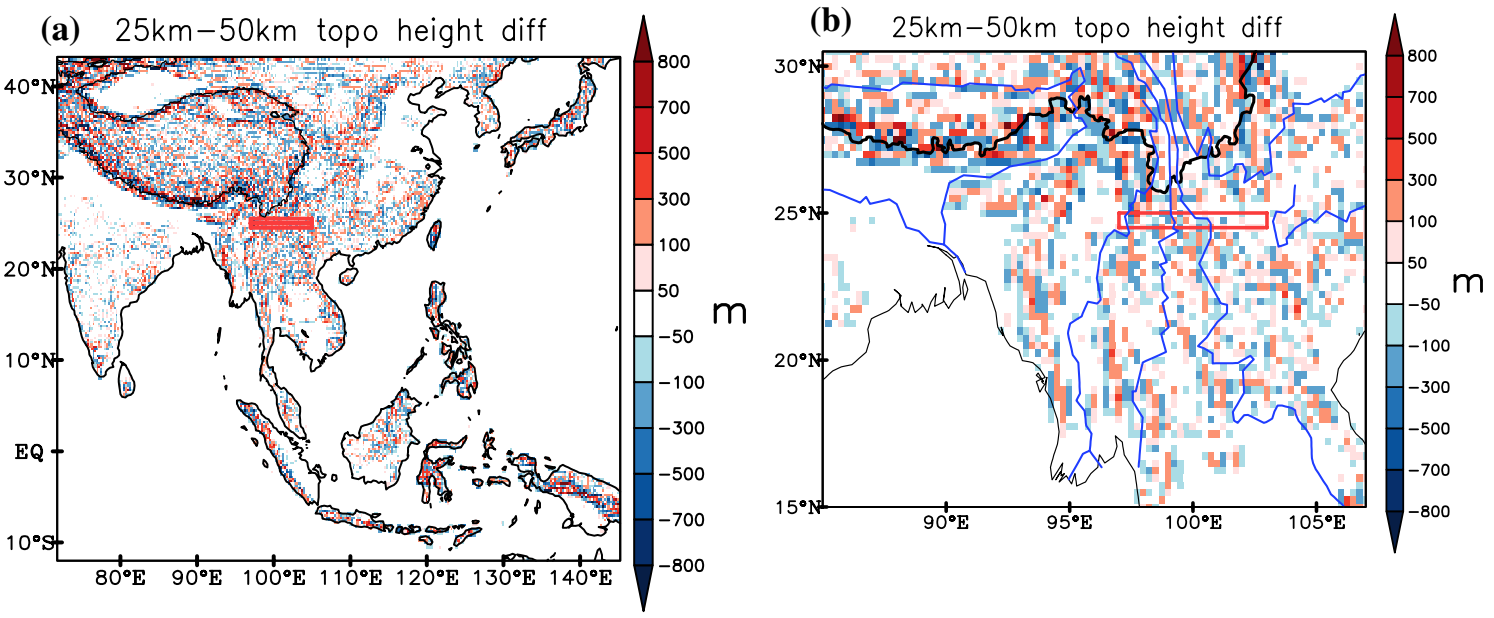

Fig. 11 Differences in orography from the R_25 km and R_50 km simulations over a the whole domain and $\mathbf{b}$ the TP. The red box shows the position of the cross-section. The solid black line is the $2000 \mathrm{~m}$ a.s.l. contour line over the TP. The main river valleys are shown as blue lines

upward in the R_25 km simulation. In general, there was a vertical downward flow of air in the $\mathrm{R} \_25 \mathrm{~km}$ simulation in southeast TP compared with the R_50 km simulation. The center of the difference in downward movement matched with the enlarged valleys. These results indicate that less air is forced to flow upward over the TP in the R_25 km simulation as a result of the reduced blocking effect of the Hengduan Mountains.

To answer the question of why it is drier over the TP in the $\mathrm{R} \_25 \mathrm{~km}$ simulation, we analyzed the water transport 
(a) $10 \mathrm{~m}$ wind topo cross section DJF

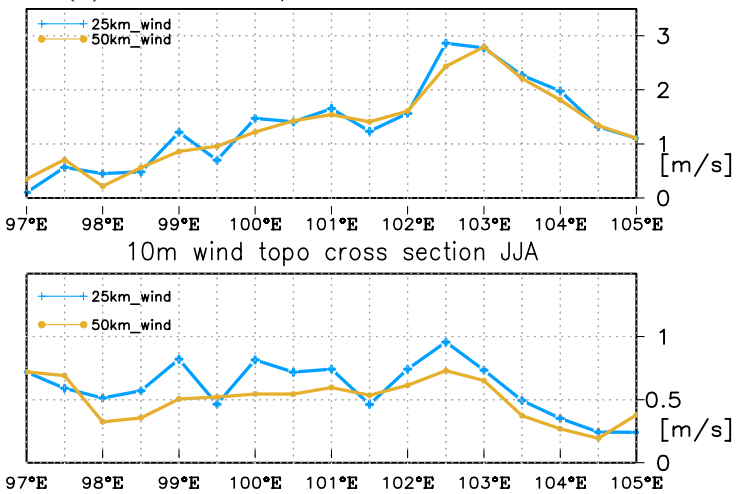

(b) topo height cross section

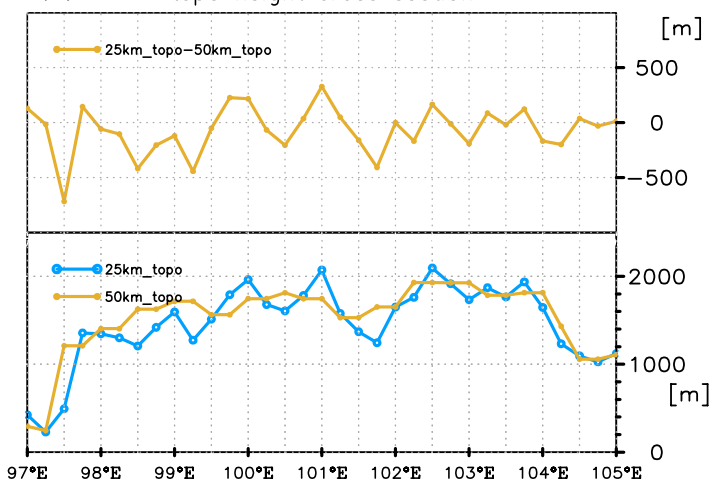

Fig. 12 Cross-section of the topography and wind speed at $10 \mathrm{~m}$ from the $\mathrm{R} \_25 \mathrm{~km}$ (blue line) and R_50 km (yellow line) simulations in a DJF and $\mathbf{b}$ JJA. The resolution of the topography is $25 \mathrm{~km} \times 25 \mathrm{~km}$ and the resolution of the wind speed is $50 \mathrm{~km} \times 50 \mathrm{~km}$

(a) R_25km wind $925 \mathrm{hPa}$ DJF

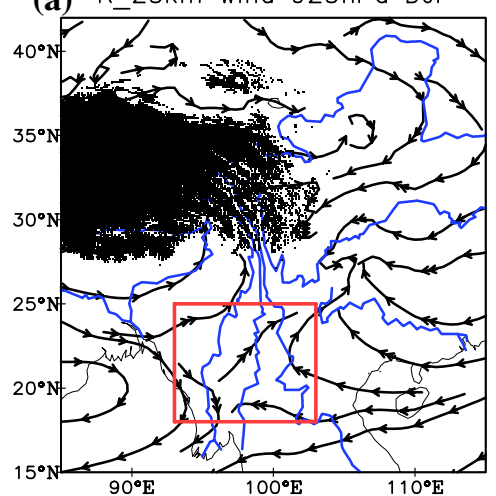

(d) R_25km wind $925 \mathrm{hPa} \mathrm{JJA}$

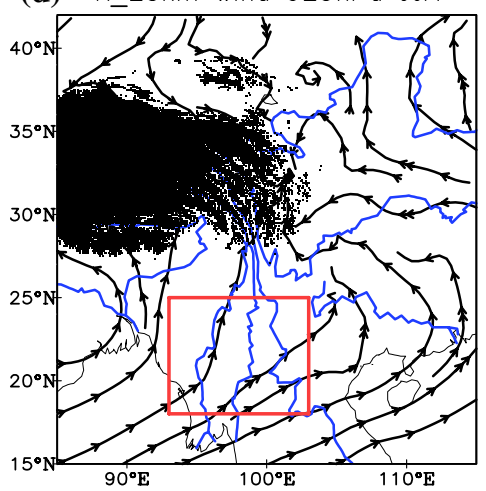

(b) R_50km wind $925 \mathrm{hPa}$ DJF

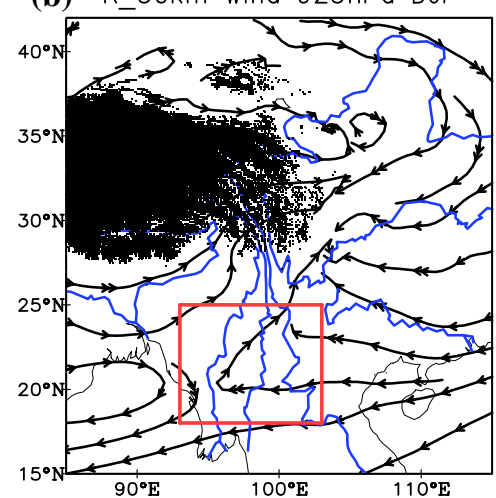

(c) (R_25km-R_50km)/R 50km wind diff $925 \mathrm{hPa}$ DJF

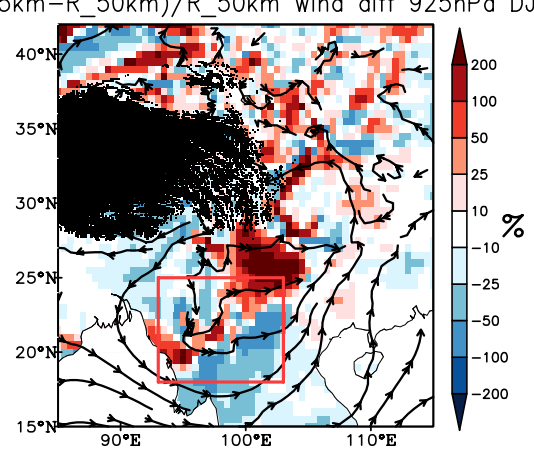

(e) R_50km wind $925 \mathrm{hPa} J J A$

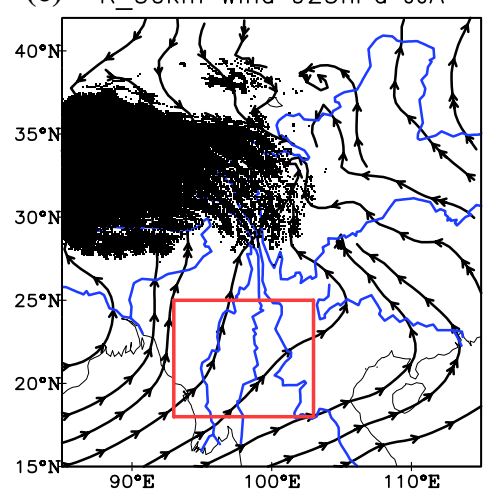

(f) (R_25km-R_50km)/R_50km wind diff $925 \mathrm{hPa} J J A$

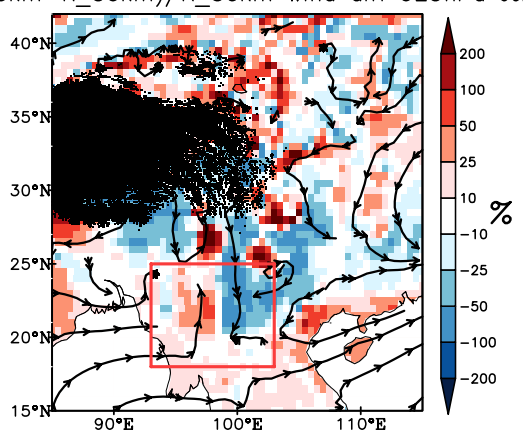

Fig. 13 Flow patterns of the wind at $925 \mathrm{hPa}$ in the a, d R_25 km simulation and $\mathbf{b}, \mathbf{e} \mathrm{R} \_50 \mathrm{~km}$ simulation and $\mathbf{c}, \mathbf{f}$ the relative differences in wind speed from the R_25 km and R_50 km simulations over the TP in DJF (a-c) and JJA (d-f). The direction (as streamlines) and speed difference (as colors) of the winds are shown. The black shading is the area $>3000 \mathrm{~m}$ a.s.l. The main river valleys are shown as blue lines and the red boxes show the area of high horizontal wind direction shear of the whole air column, comprising vapor, liquid water, and ice. The water vapor transported to the southern TP via the river valleys, for example, the Brahmaputra valley. The transport of water over the TP was smaller in the R_25 km simulation than in the R_50 km simulation in both DJF and JJA (Fig. 15). Figure 15 shows that $>5 \%$ less water was 
(a) R_25km-R_50km geo diff $200 \mathrm{hPa}$ DJF

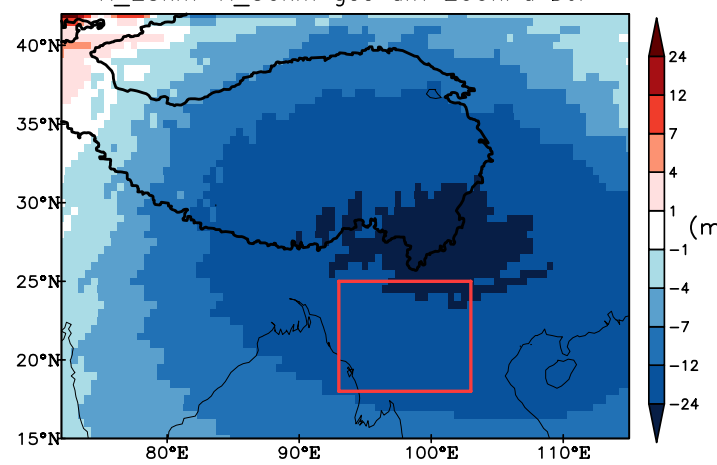

(c) R_25km-R_50km geo diff 500hPa DJF

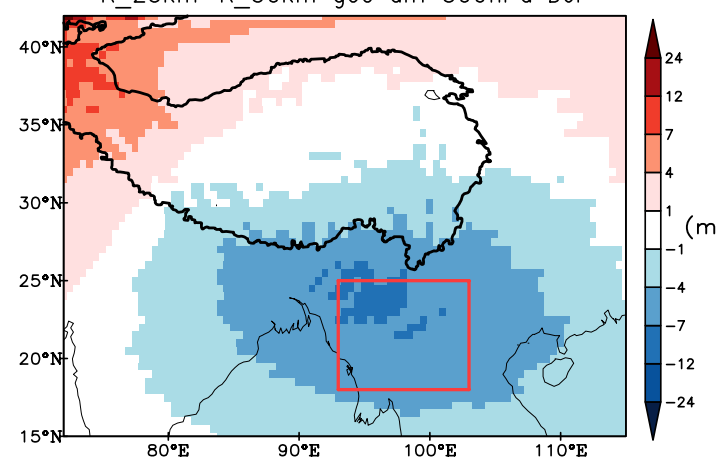

(e)

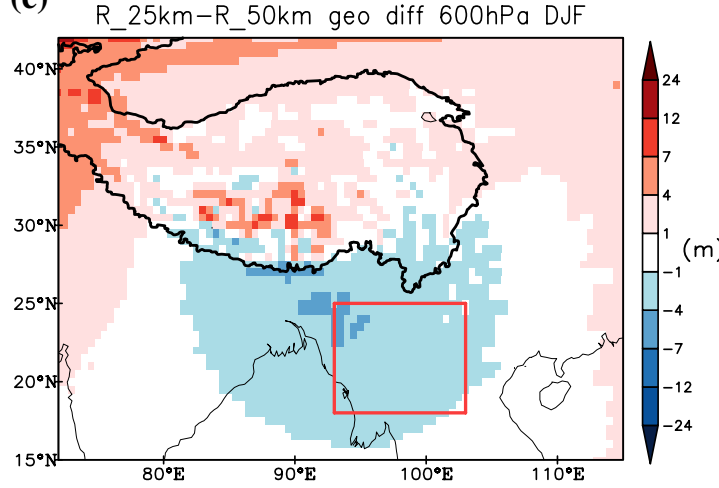

(g) R_25km-R_50km geo diff $850 \mathrm{hPa}$ DJF

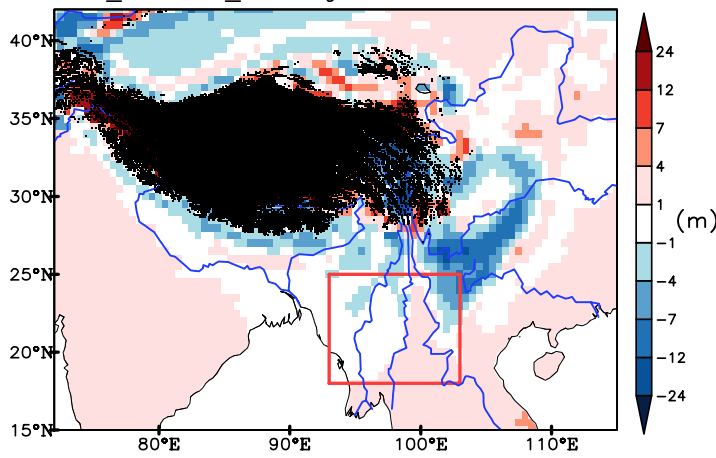

Fig. 14 Geopotential height differences at a 200, c 500, e 600 and g $850 \mathrm{hPa}$ in DJF and at b 200, d 500, f 600 and $\mathbf{h ~} 850 \mathrm{hPa}$ in JJA between the R_25 km and R_50 km simulations. The main river val- (b)

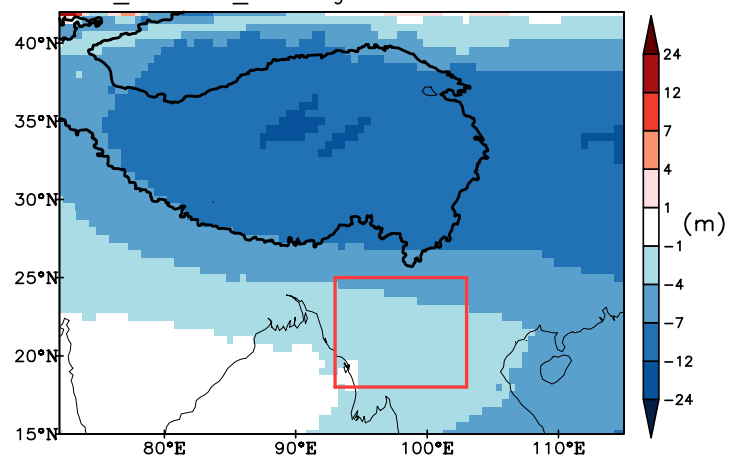

(d) R_25km-R_50km geo diff 500hPa JJA

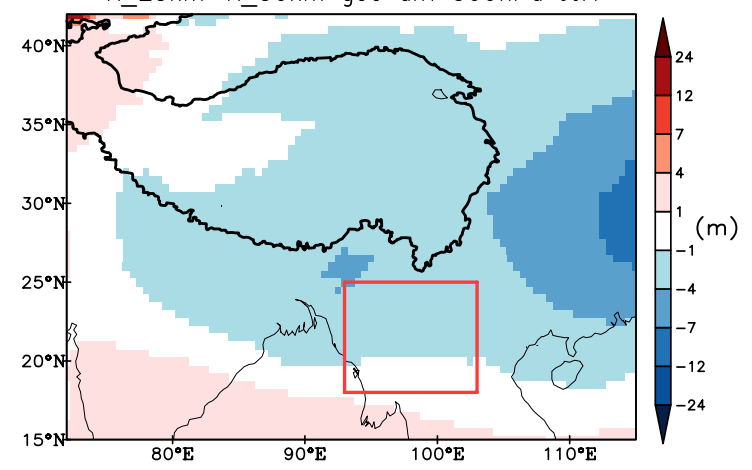

(f)

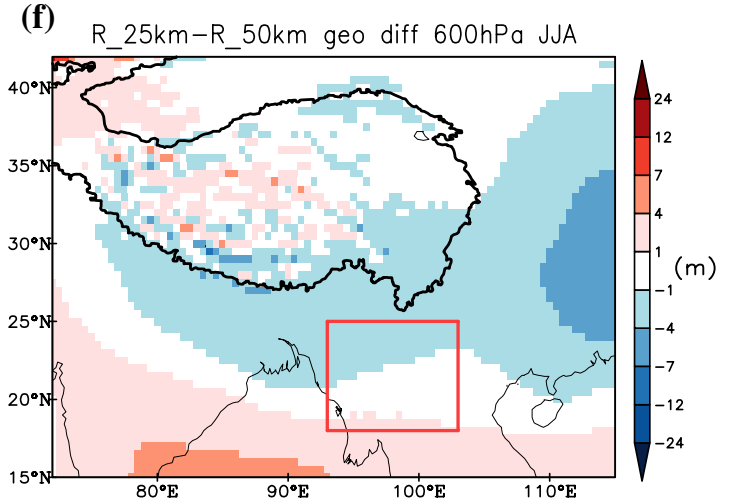

(h) R_25km-R_50km geo diff $850 \mathrm{hPa} \mathrm{JJA}$

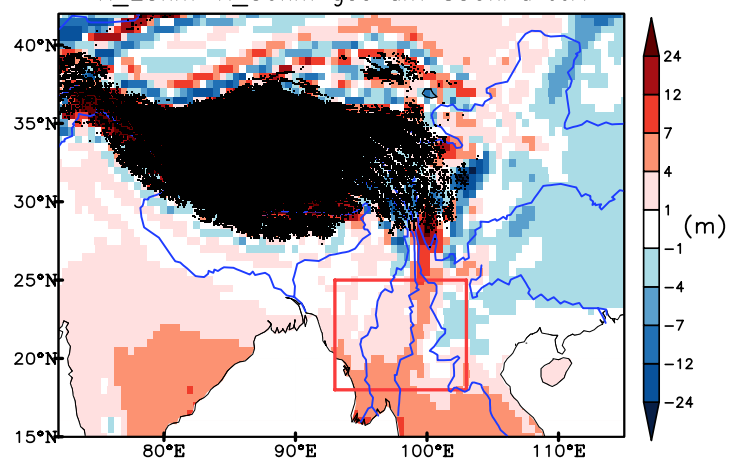

leys are shown as blue lines and the red boxes show the area of high horizontal wind direction shear 
(a) R_25km (qd+qw+qi)box DJF

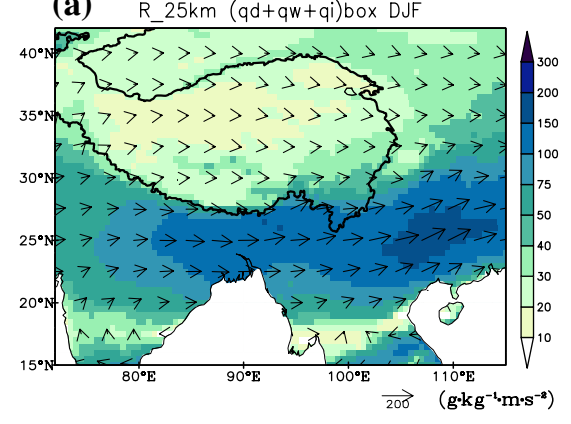

(d) $\quad$ R_25km (qd+qw+qi)box JJA

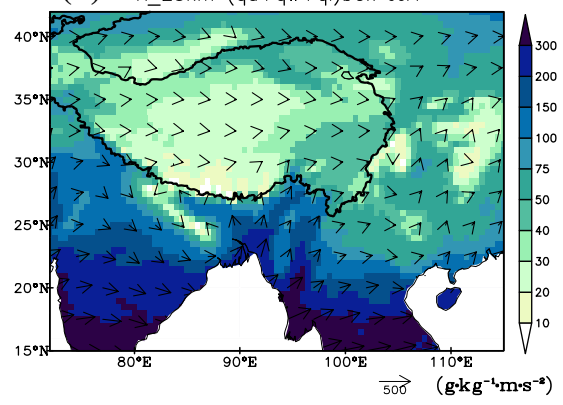

(b) R_50km (qd+qw+qi)box DJF

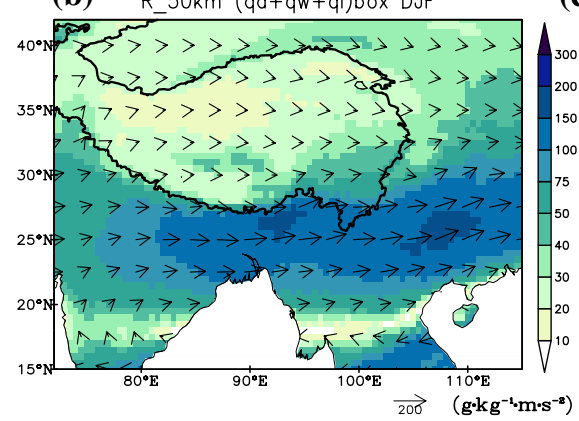

(c)

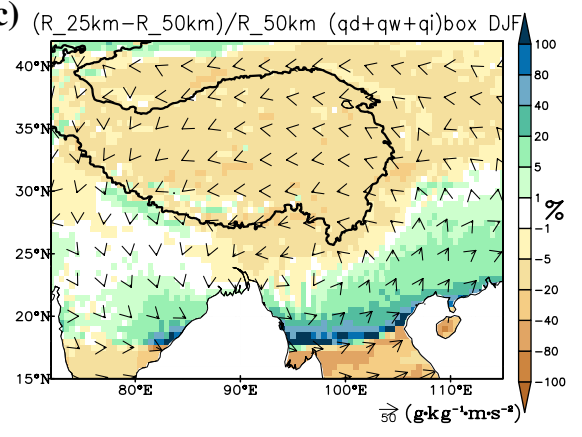

(e) R_50km (qd+qw+qi)box JJA

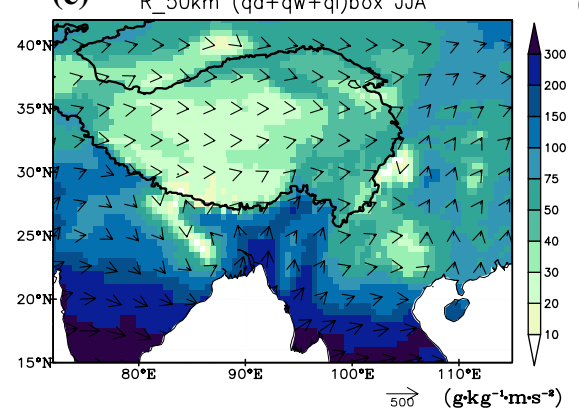

(f)

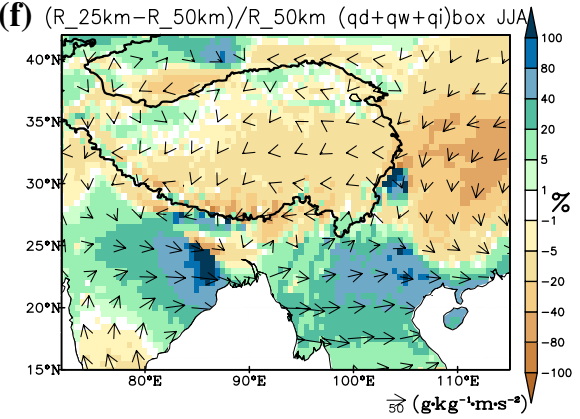

Fig. 15 Basic flow of the integrated components of water $\left(q_{\mathrm{d}}+q_{\mathrm{w}}+q_{\mathrm{i}}\right)$ transport over the whole air column from the a, $\mathbf{d}$ R_25 km simulation, the b, e R_50 km simulation and $\mathbf{c}, \mathbf{f}$ the dif- ferences between the R_25 km and R_50 km simulations. The flow direction is shown by the arrows and the flow value by colors transported onto the TP in DJF, especially in the southern TP. By contrast, the amount of water vapor transported in the southern Hengduan Mountains increased by $>20 \%$.

This analysis shows that, because the size of the rivers and valleys was increased in the R_25 km simulation, the blocking effects of the Hengduan Mountains were decreased. As a result, less air was forced to flow up over the TP, decreasing the amount of water transported across the TP. Accordingly, there was less precipitation over the TP in the R_25 km simulation.

\subsection{Main mechanism behind the differences in the $\mathbf{2} \mathbf{m}$ temperature over the TP between the $R \_25$ km and $R \_50$ km simulations}

The ground temperature responds rapidly to the radiation-it takes only a few hours to heat up the ground surface (Roeckner et al. 2003). Therefore, we analyzed the difference in the $2 \mathrm{~m}$ temperature between the R_25 km and R_50 km simulations mainly through the radiation factor.

Cloud cover has a strong connection with surface temperature over the TP (Zhou and Li 2002). To investigate the differences in cloud cover, we calculated the relative differences in cloud cover in the same way as the relative differences in precipitation. To show the effect of cloud cover on downward radiation, we also calculated the relative differences in the amount of downward longwave radiation emitted by clouds. There was a stable amount of decreased cloud cover over most of East Asia and reduced differences of up to $10 \%$ in longwave radiation over the TP in DJF (Fig. 16). Due to the East Asia summer monsoon, when the water vapor content of the atmosphere was extremely high (> 80\%), the magnitude of differences in cloud cover in JJA is smaller. The relative differences in cloud cover and downward longwave radiation were smaller in JJA than in DJF.

In order to analyze the connection between the downward radiation and the surface temperature, we analyzed the mean variability in the differences in downward radiation between the R_25 km and R_50 km simulations as well as the variability in the differences in the net shortwave, net longwave and downward longwave radiation over the TP. The net radiation is the sum of the net shortwave radiation and the net longwave radiation. Based on the time series of the variability in radiations, the downward longwave radiation has a significant connection with the net longwave radiation, passed statistically significance test at the 95\% confidence level (Fig. 17). The net shortwave radiation oscillated around $4 \mathrm{Wm}^{-2}$, whereas the mean shift in the net longwave radiation was about $-5 \mathrm{Wm}^{-2}$. This means that the increase in the amount of net shortwave radiation gained by the land surface due to the reduced cloud cover in the $\mathrm{R} \_25 \mathrm{~km}$ simulation was less than the 
(a) (R_25km-R_50km)/R_50km cloud cover diff DJF

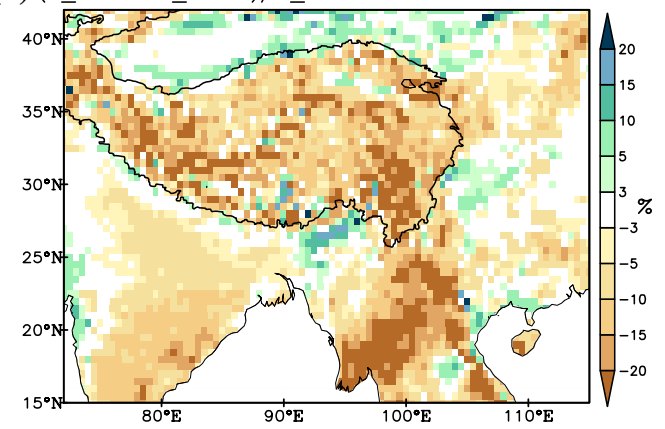

(c) (R_25km-R_50km)/R_50km downward long wave rad DJF

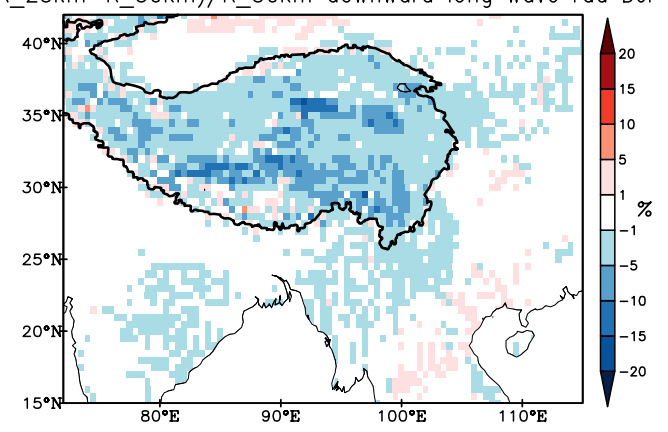

(b) $\left(R_{-} 25 \mathrm{~km}-\mathrm{R} \_50 \mathrm{~km}\right) / R_{-} \_50 \mathrm{~km}$ cloud cover diff JJA

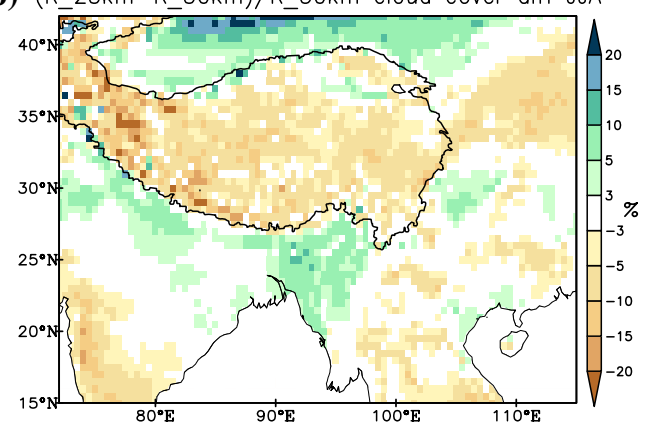

(d) (R_25km-R_50km)/R_50km downward long wave rad JJA

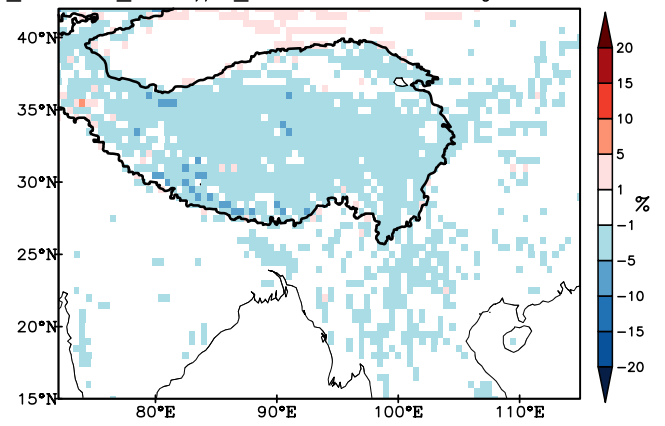

Fig. 16 Relative differences in cloud cover in $\mathbf{a}$ DJF and $\mathbf{b}$ JJA between the R_25 km and R_50 km simulations and the relative differences in downward longwave radiation in $\mathbf{c}$ DJF and $\mathbf{d} J J A$

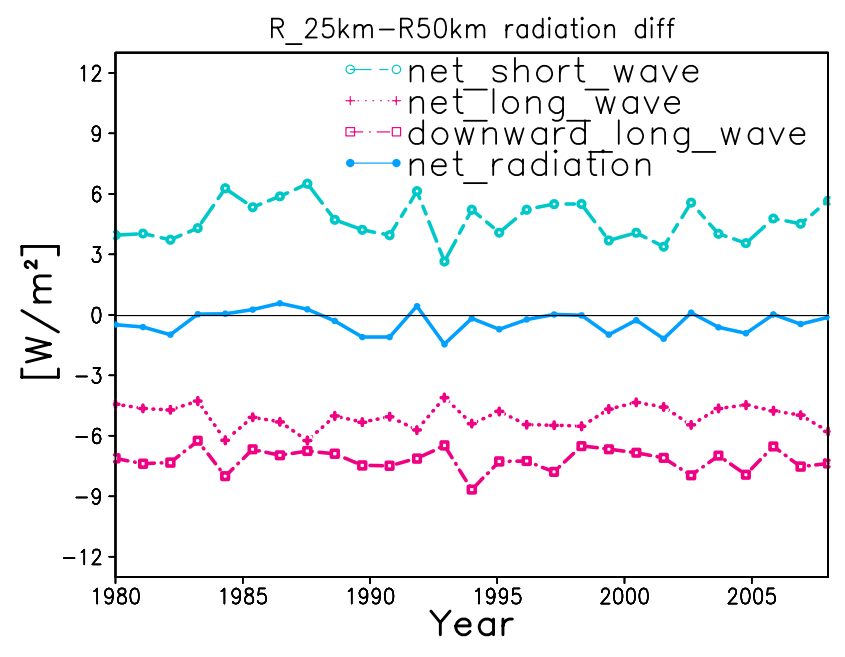

Fig. 17 Time series of the mean differences between the $\mathrm{R} \_25 \mathrm{~km}$ and $\mathrm{R} \_50 \mathrm{~km}$ simulations in downward radiation, net shortwave radiation, net longwave radiation and net radiation over the TP. The time correlation coefficient between downward longwave radiation and net longwave radiation is 0.51 , which is statistically significant at the $95 \%$ confidence level based on the two-tailed t-test

decrease in the amount of net longwave radiation caused by the reduced clouds. The net radiation difference was slightly negative over the period 1980-2007. The mean difference in net shortwave radiation over 28 years was
$4.5 \mathrm{Wm}^{-2}$ over the TP; the mean difference in downward longwave radiation was $-7.1 \mathrm{Wm}^{-2}$ and the mean net difference in radiation was $-0.4 \mathrm{Wm}^{-2}$, which is relatively high for one season. Therefore, as a result of the decreased amount of cloud cover in the R_25 km simulation, the amount of energy that the land surface gained from net shortwave radiation was less than the decrease in the amount of net longwave radiation caused by the clouds. The surface temperature was, therefore, lower over the TP in the R_25 km simulation.

The latent and sensible heat fluxes are the main mechanisms by which energy is returned from the surface of the Earth into the atmosphere (Roeckner et al. 2003). While the differences in surface temperature over the TP were greater in DJF than in JJA, the differences in both the sensible and latent heat fluxes over the TP were greater in DJF than in JJA (Fig. 18). Even though the stability of the atmosphere, cold (warm) advection affects the return of energy from the surface to the atmosphere, the patterns in the difference in heat fluxes roughly match the difference in the $2 \mathrm{~m}$ temperature-for example, weaker sensible and latent heat fluxes are found over the southern TP in the $\mathrm{R} \_25 \mathrm{~km}$ simulation than in the R_50 km simulation, which leads to the colder $2 \mathrm{~m}$ temperature in the $\mathrm{R} \_25 \mathrm{~km}$ simulation in the southern TP. 
(a)

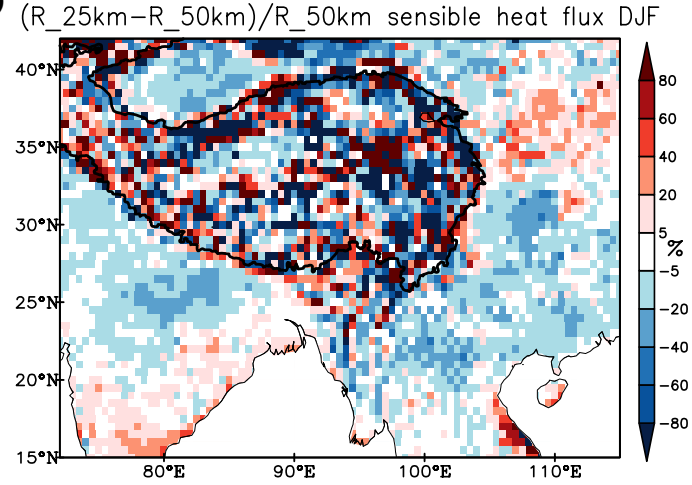

(c)

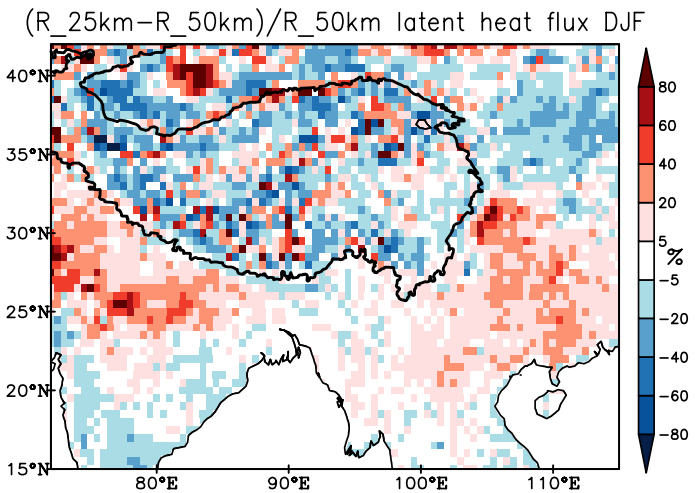

(b)

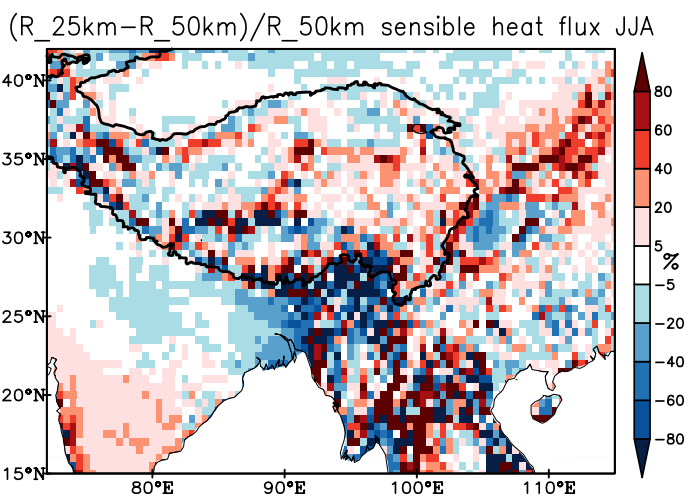

(d)

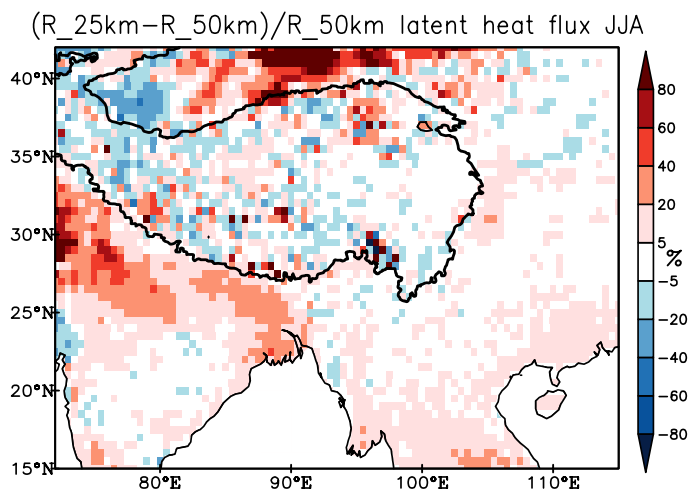

Fig. 18 Relative differences between the R_25 km and R_50 km simulations of a the sensible heat flux in DJF and $\mathbf{b}$ JJA and in the relative difference in latent heat flux in $\mathbf{c}$ DJF and $\mathbf{d}$ JJA

\section{Summary and discussions}

Previous work has documented added value provided by simulations of RCMs with increased horizontal resolution. However, there have been a relatively small number of analyses for areas with complex orographic features, such as the edge of the TP. We identified the main mechanism leading to differences in REMO simulations at 25 and $50 \mathrm{~km}$ resolution over the TP. The results showed that topographic differences play a crucial part in affecting the surface air flow and the redistribution of the transport of atmospheric water vapor over the Brahmaputra and Irrawaddy valleys-the main source of water vapor for the southern TP. This study shows the benefit gained by using a higher resolution for precipitation in REMO simulations. However, although we identified the acting main mechanism, a quantitative analysis is still needed to identify the magnitude of the orographic effects. Our results can be summarized as follows.

1. We validated the $2 \mathrm{~m}$ temperature and precipitation results of REMO simulations with resolutions of 25 and $50 \mathrm{~km}$ against MERRA-2 reanalysis data. The patterns in the $2 \mathrm{~m}$ temperature and precipitation from both the $\mathrm{R} \_25 \mathrm{~km}$ and $\mathrm{R} \_50 \mathrm{~km}$ simulations were comparable with MERRA-2. Both simulations showed a pronounced cold and wet bias over the TP, especially in the southern and western TP. The $25 \mathrm{~km}$ resolution simulation produced colder and drier conditions over the TP than the $50 \mathrm{~km}$ resolution simulation in the southern and western TP. The precipitation from the $25 \mathrm{~km}$ resolution simulation and $2 \mathrm{~m}$ temperature from the $50 \mathrm{~km}$ resolution simulation were closer to the MERRA-2 dataset. The distribution of precipitation showed that the main transport paths for atmospheric water vapor over the southern TP were via the Brahmaputra and Irrawaddy valleys.

2. The experiments differ only in representation of topography, all other land parameters (e.g., vegetation characteristics, soil texture) are the same. The greatest differences in topography occurred along the edge of the TP. The Himalaya and Hengduan Mountains are S-shaped mountain ranges, which means that the Brahmaputra valley, the main transport path for water to the southern TP, is a backwater area and there is an increase in the flow of air containing water vapor over the Himalaya. The cross-section over the wind direction shear area showed a decreased blocking effect by the Hengduan Mountains in the $25 \mathrm{~km}$ resolution simulation, which means that a large amount of air escaping from the blocking by the 
effect of the Hengduan Mountains in the R_25 km simulation, whereas air flows up over the TP in the R_50 km simulation. This, in turn, means that a lower amount of atmospheric water vapor was transported onto the TP.

3. The decreased amount of atmospheric water vapor, together with the reduced upward movement of air, caused a reduction in the total cloud cover, which led to a reduced amount of downward longwave radiation caused by clouds. This phenomenon was seen over the TP during almost all the study period, particularly during the season with the least amount of cloud (DJF). The amount of net shortwave radiation that the land surface gained as a result of reduced cloud cover in the R_25 km simulation was less than the decrease in the amount of downward longwave radiation emitted by clouds. The net difference in radiation over the TP was usually negative over the study period, which resulted in lower surface temperatures and a decreased heat flux. As a result, the R_25 km simulation was drier and colder over the TP than the R_50 km simulation, especially in the southern TP.

A higher horizontal resolution, therefore, has complex effects on the results of simulations. Almost all the dynamic and thermodynamic processes in the model are affected. Our results show that the impact of topography is one of the main factors influencing the $2 \mathrm{~m}$ temperature and the precipitation in regions with complex orographic effects. We analyzed the fine-scale orographic effects on the transport of atmospheric water vapor over the Hengduan Mountains and the Brahmaputra valleys, which are the most important paths for water transport to the TP. For the western TP, close to the boundary of the simulation, the results could lead to model boundary issues. The impact of topography in the western TP requires further analysis.

\footnotetext{
Acknowledgements We thank anonymous reviewers for comments and suggestions that helped to improve the manuscript. Also, we are very thankful to Dr. Diana Rechid at GERICS for her discussions. This work is supported by the project "Numerical study of the surface energy and mass balance and the characteristics of boundary layer for a mountain glacier" supported by National Natural Science Foundation of China (No. 41371095), the project S1 (Climate Models as Metrics) of the Collaborative Research Centre TRR 181 Energy Transfer in Atmosphere and Ocean program funded by the German Research Foundation, EC project PRIMAVERA under the grant agreement no. 641727 and the state assignment of FASO Russia (theme No. 0149-2018-0014). We thank the MERRA for providing the high-resolution $2 \mathrm{~m}$ temperature and precipitation gridded data. We thank the Climate System Department at GERICS for the consultations on the REMO model. Simulations were done at the German Climate Computing Center (DKRZ). This study is also funded by "the Priority Academic Program Development of Jiangsu Higher Education Institutions" (PAPD).
}

\section{Compliance with ethical standards}

Conflict of interest We declare that we have no conflicts of interest regarding the publication of this paper.

\section{References}

Asselin R (1972) Frequency filter for time integrations. Mon Wea Rev 100:487-490

Bao X, Zhang F (2013) Evaluation of NCEP-CFSR, NCEP-NCAR, ERA-Interim, and ERA-40 reanalysis datasets against independent sounding observations over the tibetan plateau. J Clim 26:206-214

Borscheid P (2015) Temporal and spatial scaling impacts on extreme precipitation. Atmos Chem Phys 15:2157-2196

Casanueva A et al (2015) Daily precipitation statistics in a EUROCORDEX RCM ensemble: added value of raw and bias-corrected high-resolution simulations. Clim Dyn 31:1-19

Claussen M, Lohmann U, Roeckner E, Schulzweida U (1994) A global data set of land-surface parameters. MPI Report 135

Cui X, Langmann B, Graf H-F (2007) Summer monsoonal rainfall simulation on the Tibetan Plateau with a regional climate model using a one-way double-nesting system. Sola 3:49-52

Davies HC (1983) Limitations of some common lateral boundary schemes used in regional NWP models. Mon Weather Rev 111:1002-1012

Dee DP et al (2011) The ERA-Interim reanalysis: configuration and performance of the data assimilation system. Q J R Meteorol Soc 137:553-597

Eggert B, Berg P, Haerter JO, Jacob D, Moseley C (2015) Temporal and spatial scaling impacts on extreme precipitation. Atmos Chem Phys 15:5957-5971

Feng L, Zhou T (2012) Water vapor transport for summer precipitation over the Tibetan Plateau: multidata set analysis. J Geophys Res Atmos 117:20114

Gao Y, Leung LR, Zhang Y, Cuo L (2015a) Changes in moisture flux over the Tibetan Plateau during 1979-2011: insights from a highresolution simulation. J Clim 28:4185-4197

Gao Y, Xu J, Chen D (2015b) Evaluation of WRF mesoscale climate simulations over the Tibetan Plateau during 1979-2011. J Clim 28:2823-2841

Gao Y, Xiao L, Chen D, Chen F, Xu J, Xu Y (2017) Quantification of the relative role of land-surface processes and large-scale forcing in dynamic downscaling over the tibetan plateau. Clim Dyn 48:1705-1721

Ge F, Sielmann F, Zhu X, Fraedrich K, Zhi X, Peng T, Wang L (2017) The link between Tibetan Plateau monsoon and Indian summer precipitation: a linear diagnostic perspective. Clim Dyn 49:4201-4215

Hagemann S (2002) An improved land surface parameter dataset for global and regional climate models. MPI Report 336

Hagemann S, Botzet M, Dümenil L, Machenhauer B (1999) Derivation of global GCM boundary conditions from $1 \mathrm{~km}$ land use satellite data. MPI Report 289

Jacob D, Podzun R (1997) Sensitivity studies with the regional climate model REMO. Meteorol Atmos Phys 63:119-129

Jacob D et al (2007) An inter-comparison of regional climate models for Europe: model performance in present-day climate. Clim Change 81:31-52

Jacob D et al (2012) Assessing the transferability of the regional climate model REMO to different coordinated regional climate downscaling experiment (CORDEX) regions. Atmosphere 3:181-199 
Jacob D et al (2013) EURO-CORDEX: new high-resolution climate change projections for European impact research. Reg Environ Change 14:563-578. https://doi.org/10.1007/s10113-013-0499-2

Jacob D et al (2014) EURO-CORDEX: new high-resolution climate change projections for European impact research. Reg Environ Change 14:563-578

Ji Z, Kang S (2013) Double-nested dynamical downscaling experiments over the Tibetan Plateau and their projection of climate change under two RCP scenarios. J Atmos Sci 70:1278-1290

Kumar P, Podzun R, Hagemann S, Jacob D (2014a) Impact of modified soil thermal characteristic on the simulated monsoon climate over south Asia. J Earth Syst Sci 123:151-160

Kumar P, Sein D, Cabos W, Jacob D (2014b) Improvement of simulated monsoon precipitation over South-Asia with a regionally coupled model ROM. Int Balt Earth Secr Publ 3:16

Kumar P, Kotlarski S, Moseley C, Sieck K, Frey H, Stoffel M, Jacob D (2015) Response of Karakoram-Himalayan glaciers to climate variability and climatic change: a regional climate model assessment. Geophys Res Lett 42:1818-1825

Luca AD, Elía RD, Laprise R (2012) Potential for added value in precipitation simulated by high-resolution nested regional climate models and observations. Clim Dyn 38:1229-1247

Lucas-Picher P, Wulff-Nielsen M, Christensen JH, Mottram R, Simonsen SB (2012) Very high resolution regional climate model simulations over Greenland: identifying added value. J Geophys Res Atmos 117:262-269

Majewski D (1991) The Europa-Modell of the Deutscher Wetterdienst. ECMWF Seminar on numerical methods in atmospheric models, 1991. pp 147-191

Maussion F, Scherer D, Mölg T, Collier E, Curio J, Finkelnburg R (2014) Precipitation seasonality and variability over the Tibetan Plateau as resolved by the High Asia reanalysis. J Clim 27:1910-1927

Miliaresis GC, Argialas DP (1999) Segmentation of physiographic features from the global digital elevation model/GTOPO30. Comput Geosci 25:715-728

Molod A, Takacs L, Suarez M, Bacmeister J (2015) Development of the GEOS-5 atmospheric general circulation model: evolution from MERRA to MERRA2. Geosci Model Dev 7:1339-1356

Palazzi E, Hardenberg J, Provenzale A (2013) Precipitation in the Hindu-Kush Karakoram Himalaya: observations and future scenarios. J Geophys Res Atmos 118:85-100

Prein AF et al (2016) Precipitation in the EURO-CORDEX 0.11 and $0.44^{\circ}$ simulations: high resolution, high benefits? Clim Dyn 46:383-412

Rasmussen R et al (2011) High resolution coupled climate-runoff simulations of seasonal snowfall over Colorado: a process study of current and warmer climate. J Clim 24:3015-3048

Rechid D, Hagemann S, Jacob D (2009a) Sensitivity of climate models to seasonal variability of snow-free land surface albedo. Theoret Appl Climatol 95:197-221

Rechid D, Raddatz TJ, Jacob D (2009b) Parameterization of snow-free land surface albedo as a function of vegetation phenology based on MODIS data and applied in climate modelling. Theor Appl Climatol 95:245-255

Redler R (2015) YAC 1.2. 0: An extendable coupling software for earth system modelling. Geoscientific Model Development

Ritter B, Geleyn J-F (1992) A comprehensive radiation scheme for numerical weather prediction models with potential applications in climate simulations. Mon Weather Rev 120:303-325

Roeckner E et al (2003) The atmospheric general circulation model ECHAM 5. PART I: Model description
Saeed F, Hagemann S, Jacob D (2009) Impact of irrigation on the South Asian summer monsoon. Geophys Res Lett 36:L20711. https://doi.org/10.1029/2009GL040625

Saeed F, Hagemann S, Jacob D (2012) A framework for the evaluation of the South Asian summer monsoon in a regional climate model applied to REMO. Int J Climatol 32:430-440. https://doi. org/10.1002/joc.2285

Sein DV, Koldunov NV, Pinto JG, Cabos W (2014) Sensitivity of simulated regional Arctic climate to the choice of coupled model domain. Tellus A 66:23966. https://doi.org/10.3402/tellu sa.v66.23966

Sein DV et al (2015) Regionally coupled atmosphere-ocean-sea icemarine biogeochemistry model ROM: 1 . Description and validation. J Adv Model Earth Syst 7:268-304

Simmons AJ, Burridge DM (1981) An energy and angular-momentum conserving vertical finite-difference scheme and hybrid vertical coordinates. Mon Weather Rev 109:758-766

Su F, Duan X, Chen D, Hao Z, Cuo L (2013) Evaluation of the global climate models in the CMIP5 over the Tibetan Plateau. J Clim 26:3187-3208

Taylor KE (2001) Summarizing multiple aspects of model performance in a single diagram. J Geophys Res Atmos 106:7183-7192. https ://doi.org/10.1029/2000jd900719

Tiedtke M (1989) A comprehensive mass flux scheme for cumulus parameterization in large-scale models. Mon Weather Rev 117:1779-1800

Wang QW, Tan ZM (2014) Multi-scale topographic control of southwest vortex formation in Tibetan Plateau region in an idealized simulation. J Geophys Res Atmos 119:20

Wang A, Zeng X (2012) Evaluation of multireanalysis products with in situ observations over the Tibetan Plateau. J Geophys Res Atmos 117:D05102. https://doi.org/10.1029/2011JD016553

Winiger M, Gumpert M, Yamout H (2005) Karakorum-Hindukushwestern Himalaya: assessing high-altitude water resources. Hydrol Process 19:2329-2338

Wu J, Gao X (2013) A gridded daily observation dataset over China region and comparison with the other datasets. Chin J Geophy 56:1102-1111

Wu G, Guan Y, Wang T, Liu Y, Yan J, Mao J (2011) Vortex genesis over the Bay of Bengal in spring and its role in the onset of the Asian summer monsoon. Sci China Earth Sci 54:1-9

Xie SP, Xu H, Saji NH, Wang Y, Liu WT (2008) Role of narrow mountains in large-scale organization of Asian monsoon convection. J Clim 19:3420-3429

Xu X, Lu C, Shi X, Gao S (2008) World water tower: an atmospheric perspective. Geophys Res Lett 35:L20815. https://doi. org/10.1029/2008GL035867

Xu Y, Gao X, Shen Y, Xu C, Shi Y, Giorgi F (2009) A daily temperature dataset over China and its application in validating a RCM simulation. Adv Atmos Sci 26:763-772

Zhang Y, Gao H, Lammel G (2005) Simulation of monsoon seasonal variation of regional climate model REMO in East Asia (in Chinese). Clim Environ Res 10:41-55

Zhou T-j, Li Z (2002) Simulation of the East Asian summer monsoon using a variable resolution atmospheric GCM. Clim Dyn 19:167-180

Zhu X, Wang W, Fraedrich K (2013) Future climate in the Tibetan Plateau from a statistical regional climate model. J Clim 26:10125-10138 